\title{
The impact of the COVID-19 pandemic on California farmworkers: Better local data collection and reporting will improve strategic response
}

\author{
Edward Kissam \\ 1285 N. Via Paraiso, Palm Springs, CA 94602, USA \\ E-mail:edkissam@me.com
}

\begin{abstract}
Providing the public with relevant and reliable statistical information about the impact of COVID-19 on vulnerable populations is a crucial weapon in effective public health system response. This article examines the reporting challenges confronted by local public health agencies based on a case study of farmworker communities of the San Joaquin Valley, Eastern Coachella Valley, and Salinas Valley. The analysis includes a quantitative estimate of the impact COVID-19 has on farmworker households and highlights how socioeconomic factors and housing conditions give rise to health disparities.

The importance of local data collection and reporting as the foundation for a national epidemiological tracking system is emphasized. Current shortcomings stemming from flawed national guidance and local political pressures are noted. The discussion includes detailed recommendation for improved reporting including: more systematic tabulations of available data, an expanded set of indicators to monitor public health system response, promising approaches to improve representativeness of test-derived data on COVID-19 by making it easier to access testing and support services, coupled with messaging to broaden farmworkers' and other socio-politically marginalized populations' willingness to seek testing. Understanding the challenges faced and lessons learned in the San Joaquin Valley region have practical implications for a wide range of countries.
\end{abstract}

Keywords: Farmworkers, San Joaquin Valley, California, COVID-19, testing, CDC, messaging, outbreak, hotspot, health equity, COVID-19 dashboards, indicators, monitoring, contact-tracing, case investigation, public health system, local government, congregate housing, crowded housing

\section{Introduction}

Relevant and reliable statistical information about the impact of COVID-19 on vulnerable populations is a crucial weapon for effective public health system response in fighting the pandemic in local communities, in states, nationally, and globally. Improved data collection, analysis, and dissemination of tabulations of statistical data to the public cannot be seen as a luxury because a key objective in the current battle against COVID-19 is to successfully modify public social behavior and to draw a broad spectrum of non-governmental organizations into partnerships that contribute effectively to a collective response.
I discuss the challenges confronted by local level public health agencies in configuring their public reporting to make the best possible contributions to the collective response to COVID-19 as it spreads through a vulnerable population in the San Joaquin Valley of California - immigrant farmworkers and their families. Most farmworkers in the region (84\%) are long-term settled immigrants in low-income households, many of whom $(57 \%)$ live in mixed-status households that include undocumented immigrants [1]. Despite federal and state government efforts to overcome the pervasive socioeconomic and sociopolitical barriers farmworkers face, I show they continue to be disproportionately impacted by the COVID-19 pandemic. The issues faced 
in this major agricultural production region, and others like it, urgently need to be addressed.

The United States' public health system is highly decentralized - with states having the authority to decide and implement their own strategies for data collection and reporting. The states, in turn, often delegate responsibility for implementing COVID-19 surveillance to counties, or sub-state consortia of counties. ${ }^{1}$ While states and counties have the authority to determine their own surveillance strategy and actions, as well as detailed reporting requirements, $\mathrm{CDC}$ does require standardized reporting of the data submitted to it for national tabulation and disseminated via its National Center for Health Statistics and other routes such as its Mortality and Morbidity Weekly Report (MMWR). Because the United States' public health system relies on local data gathering, analysis and reporting, countylevel public health departments play a crucial role as a "feeder system" for national tabulations. Consequently, the integrity of higher-level state and federal statistical information rests on the functioning of their datagathering, analysis, and reporting. I explore the underlying problems and progress to date (October 15, 2020) and go on to offer suggestions for improvement.

Although county public health departments have long been the primary source of data needed for state and national statistical epidemiological analysis of infectious disease, few were well-prepared to confront the challenges they face in generating and reporting statistical data on COVID-19. Federal mis-steps in making $\mathrm{PCR} / \mathrm{molecular}$ tests widely available were the biggest initial problem. But subsequent delays in state funding and training for contact-tracers further compromised data quality as incidence of new cases increased rapidly statewide and in the San Joaquin Valley during the summer as the peak harvest season began.

This unfortunate situation stems in part from public response having been so seriously politicized - in the San Joaquin Valley, in California, in the United States and globally.

I demonstrate how improvements in current statistical analysis of the disparate impact of COVID-19 on a socio-economically disadvantaged population can improve detection of "hot spots" of COVID-19 prevalence and contribute to designing more effective interventions to reduce transmission. Lessons learned from the

\footnotetext{
${ }^{1}$ An inherent challenge for sub-state level data collection and reporting is that the size of counties, and the level and adequacy of financial resources available to local public health agencies, varies greatly - from state to state and even within each state.
}

situation in this labor-intensive agricultural region are relevant globally - especially in countries that, like this less-developed region in an advanced economy, have extensive cultural diversity and suffer from the serious economic and sociopolitical inequalities that give rise to health disparities.

This case study of statistical reporting at the local level shows how improved local-level data collection, analysis, and reporting can better contribute to strategic and operational decision-making, first, by better illuminating health disparities affecting a vulnerable population such as farmworkers and, second, by improved monitoring of public health system response so as to identify priority areas for improvement.

I conclude that innovative local initiatives to improve access to COVID-19 testing can be improved by focusing less on quantity of testing and more on making testing encounters the fulcrum for more integrated service delivery including contact-tracing and support for isolation/quarantine. This type of service integration has a positive impact on both spread of COVID19 and quality of data because it will decrease bias in the sample of individuals seeking and securing testing. Consequently, testing data will begin to more closely represent the overall population and more reliably track pandemic spread. ${ }^{2}$

At this point (October, 2020), after several crucial months of delays, nudged forward by newly-issued state regulations for reporting, some of the public health departments in the San Joaquin Valley, most notably in Fresno County, the largest county in the region, will be taking steps forward to improve data collection. Planned improvements include more widespread, free testing, increased availability of rapid-turnaround testing, and new partnerships with community-based organizations to develop multi-lingual, culturally-knowledgeable contact tracing teams to elicit better information on patterns of transmission. This shows that, despite financial constraints, progress in partnering with a broad network of community organizations is feasible when there

\footnotetext{
${ }^{2}$ Statistical reporting on COVID-19 in the U.S. relies predominantly on tabulations of cases confirmed by PCR/molecular testing. As of October, 2020, cases diagnosed by physicians or via antigen testing are considered "presumed". There is currently controversy in public health about reporting and characterization of antigen testing as reliance on antigen testing increases (Pradhan, R. et. al, "Lack of Antigen Test Reporting Leaves Country 'Blind to the Pandemic", Kaiser Health News, September 16, 2020). Reporting has generally, but not always, included sound provisions to distinguish reported cases from reported tests (so as to avoid duplication when an individual is tested, for example, both for diagnosis and certification to return to work).
} 
is the political will and organizational commitment to improve

\section{Conceptual landscape: Why does effective public dissemination of statistical information matter?}

In the current $21^{\text {st }}$ century era where widespread access to online information is paradoxically linked to equally widespread dissemination of fabricated information, it is not surprising to see that statistical analysis, reporting, and interpretation of the implications of pandemic-related information is a fiercely-contested battlefield. This is evidenced not only by public officials'vacillations and contradictory statements in messaging to the public but, also, by direct political interference at the national level in scientific reporting by CDC [2-5].

Making reliable and actionable COVID-19 information available to the public is important for sound decision-making in a country that purports to be democratic. The hope is that by providing information that can be well understood to be relevant and directly applicable to a broad spectrum of audiences, public health officials might successfully create platforms for more thoughtful and systematic civic engagement. The expected result would be improvements in health equity and more effective response as larger and betterinformed community-wide networks emerge to combat the pandemic.

The national-level conflict that has emerged in the United States about statistical reporting has been mirrored at the local level in the San Joaquin Valley with controversy about appropriate extent of dissemination of epidemiological information on outbreaks. The issue is manifest principally with respect to findings about case clusters in agricultural workplaces due to agriculture being an "essential industry" and major political force in the region [6].

Local public health systems have not adequately considered the potential utility of more systematic statistical reporting to the general public and diverse audiences (including farmworkers and other limited-English households) as a tool to improve health equity in the COVID-19 pandemic. National mainstream media such as the Washington Post, the New York Times, The Atlantic, and the Wall Street Journal have skillfully drawn on analyses by Johns Hopkins University Coronavirus Resource Center and worked diligently to configure published analyses so as to inform elite audiences but these information resources are not typically available to stakeholders such as immigrants and farmworkers or the community activists advocating on their behalf.

In summary, when one examines the landscape of information made available to either the main decision makers or the public, among the myriad challenges to be confronted in responding to the local current crisis of the COVID-19 pandemic at the local, regional, state, national, and global level is the need to re-examine traditional perspectives on

- what specific information (types of data) is most urgently needed,

- at what level of analysis - e.g. overall, by county, by zipcode, population subgroups?

- who can benefit from the information - e.g. epidemiologists, health care providers, local decision makers, employers, general public, subgroups of the general public?)

- what steps are required to assure reliability of information disseminated?

- what information is necessary to assure government accountability and effective implementation of generally agreed-upon strategies.

The notion that decisions about the kind of statistical data, analyses needed, and best ways to disseminate such information are "technical" ones best left solely to the "experts", in this case public health staff and officials, is an unfortunate one because it results in defaulting to public sector "business as usual" where innovation is discouraged. This notion also rests on the now seriously-eroded assumption that epidemiological professionalism will be unaffected by the tumultuous sociopolitical environment of the government context in which public health professionals work. Statistical policy in the battle against COVID-19 cannot be effectively "insulated" from public involvement. But, actually, it will be more useful for approaches to statistical analysis and dissemination of reporting to be developed with the goal of informing a broader spectrum of data users and responding to their information with careful consideration and discussion about how statistical analysis can most effectively drive innovation to improve intervention strategy and widespread public engagement in the collective battle against COVID- 19 .

\section{How, then, to move forward?}

First, there is extreme urgency to reconsider conventional wisdom about the specific types of statistical information needed by public sector decision-makers 
at the federal, state, and local level and by the public at large. Second, there is an urgent need to improve the quality of data collection in the "feeder system" for state and national statistical reporting: county public health departments. My observations and analyses examine the following:

- Tabulation of COVID-19 data on mode of transmission, cumulative incidence of COVID-19, trends of new cases, hospitalization rates, and case-fatality ratios for particularly vulnerable subpopulations such as farmworkers and key age cohorts: children and youth $0-15$, working-age population 16-64, elderly $65+^{3}$

- Enhanced data collection, analysis, and reporting for local communities (zipcode level analysis and sub-populations such as farmworkers) - linked to information on provision of testing, quarantine and support services, as well as quality of contacttracing

- Assuring adequate transparency and accountability in the public health system to effectively combat COVID-19 spread, mitigate morbidity, and provide a basis for informed public input and participation in planning and decision-making

\section{Tensions between analysis/reporting of information on the COVID-19 pandemic}

The first epidemiological note about what later came to be known as COVID-19 was a report of a cluster of 27 cases of a pneumonia "of unknown aetiology" at the Wuhan Seafood Wholesale Market on December 31, 2019 [7]. On that day, two doctors, Li Wenliang and Xie Linka presciently notified colleagues via social media (WeChat) of "a possible SARS" outbreak at the market. Li was soon reprimanded by local police "for spreading rumors" but eventually widely acknowledged (after his death from COVID-19 in early February, 2020) as having played an extremely valuable role in sounding the first alert. In one of Li's last interviews before his death, he said "A healthy society should not have only one kind of voice" [8]. Here, too, he showed a keen understanding of how authorities confront disease.

\footnotetext{
${ }^{3}$ The reason for these suggested reporting cut-points for age cohorts is in part due to COVID-19 seriousness in relation to age but, also, due to the agricultural labor market in the San Joaquin Valley, like many less-developed countries, having a relatively high level of teenage labor force participation and many immigrant farmworkers are committed to continued work in agriculture as long as they are able (in part because many lack access to Social Security).
}

But subsequent experience in the U.S. and in other countries shows the pros and cons of dueling narratives about COVID-19 and SARS-CoV-2 transmission. In less than a year, there have been a multitude of varying interpretations of findings from statistical analysis of available data (e.g. about the necessity and/or utility of face-covering to mitigate COVID-19 transmission $[9,10]$, proportion of COVID-19 cases that are asymptomatic $[11,12]$ and what such a ratio implies with respect to response strategy. There has also been extensive controversy about statistical reporting, regarding who can be counted as 'having died'from the disease (e.g. undetected deaths at home, classification of deaths of patients with co-morbidities).

Lessons learned to date about COVID-19 surveillance data and models based on reporting from local public health authorities and states are that, given the sensitivity of epidemiological analyses and modeling as a basis for decision-making in COVID-19 pandemic response strategy, there is utility to encouraging many statistical "voices" and analyses but that there is, also, a need to systematically report competing statistical analyses. Despite public impatience with technical caveats it is clear that backup documentation of definitions, analytic approaches, and uncertainties are crucial in order to avoid confusion and controversy.

\section{Case study: Background of COVID-19 in the San Joaquin Valley of California and other farmworker areas of the U.S.}

A region of California that has been particularly hard hit by COVID-19 is the San Joaquin Valley; and within that region a large population that has been particularly impacted by the pandemic are farmworkers and their families. The region has a multi-ethnic population of about 4.2 million, more than half of whom $(52 \%)$ are Latinx, and almost one-third (38\%) are immigrants (including, in addition to Latinx, among others, Hmong, Punjabi, and Filipinos). About 300,000 people in the region are agricultural workers and are another 350,000 are family members in farmworker households.

The COVID-19 pandemic appears to have reached the San Joaquin Valley slightly later than urban areas of the U.S. Pacific Seaboard. However, there is also some evidence that community spread had occurred earlier than had been initially believed; it is likely that sparse availability of PCR/molecular testing delayed detection of the first cases [13].

By mid-March, clusters of cases were reported in five of the eight counties in the region about at the 
point a statewide "shelter in place" order was issued by California Governor Gavin Newsom on March 18, 2020. By April 3, COVID-19 had been detected in all the counties of the region (Kern, Tulare, Kings, Fresno Madera, Merced, Stanislaus, San Joaquin). After an initial false peak in May, incidence of new cases finally peaked mid-summer in the region. As of October 5, 2020 , the cumulative number of reported cases in the region was 137,043 . Unfortunately, incidence of new cases then increased again.

\section{Why Farmworkers? - Rationale for Special Focus within Public Health System Tracking of COVID-19}

Over the past several months, a number of reports based on analyses of national, state, and local data show higher prevalence of COVID-19 among ethnic/racial minorities and worse outcomes. One of the most extensive recent reviews [14], for example, examined 79 "hotspot counties" (with $>100$ new cases during the most recent 7-day period and increases or decreases) and found that the mean ratio of number of cases for each racial/ethnic minority population to cases in the overall population in each area ranged from 2.3 for Asians to 8.5 for Native Hawaiian/Pacific Islanders with the ratio for Latinx/Hispanics being 4.4. A Kaiser Family Foundation report from August, 2020 notes that it took longer for data to become available to assess disparities related to COVID-19 outcomes but that racial/ethnic minorities also experience higher ageadjusted rates of hospitalization (5 times that of Whites) and age-adjusted mortality [15].

Cumulative incidence of COVID-19 infection and hospitalization among Latinos is disproportionately high [16] and virtually all (97\%) of California farmworkers are of Latino origin [17]. ${ }^{4}$ But analysis of the COVID-19 patterns simply in relation to racial/ethnic disparities is not enough to assure equitable COVID-19 response.

Looking at national patterns, it is clear there are numerous factors in play that contribute directly to these observed racial/ethnic disparities [18-21] and that

\footnotetext{
${ }^{4}$ Analyses of racial/ethnic health disparities in relation to COVID19 note that almost all reporting has some shortcomings due to missing data on race/ethnicity of cases. The problem is particularly serious for reporting on Latinos due to longstanding difficulties stemming from standard framing of queries on race/ethnicity separately from Hispanic origin. This probably results in systematic underestimates of COVID-19 impacts on Latino populations.
}

"structural factors" and social determinants of health are the primary factors in spread. Considering how these multiple factors interact in the distinctive context of farmworker communities provides a reminder of the practical benefits if the public health system were to generate more actionable statistical analyses on COVID-19 within this particularly vulnerable subpopulation of Latinos and use this information to shape ongoing strategy and intervention.

Mexican immigrant workers continue to be socioeconomically disadvantaged, even after more than half a century of social, economic, and health programs targeted to them. Although many unauthorized farmworkers were provided legal status by the Immigration Reform and Control Act in 1986, they are aging and, inevitably, and now make up only one-third of the farm labor force, while the majority of farmworkers still lack legal status [22].

The California farm labor force, initially concentrated in fieldwork in orchards and production of row crops, now makes up most of the labor force in animal production and in packing and processing facilities - an important consideration in the context of COVID-19. Agricultural production in California is less seasonal than in other parts of the U.S. due to the diversity of crops in the state but there remain major peaks (AugustSeptember) and troughs (December-January) that affect farmworkers' risk of COVID-19 exposure over the course of the year.

Another important consideration is that about $40 \%$ of California farmworkers are employed by farm labor contractors [22]. These labor contractors play an important role in the labor market by moving crews from one production site to another - a practice that contributes to social network mixing and may, therefore, be important in patterns of COVID-19 transmission.

Employment in an essential industry where social distancing is difficult and uneven and where crowded housing is prevalent makes the burden of COVID19 even higher for farmworkers than for the overall Latino population. California took a step forward in doing by issuing a "health equity" metric for assessing counties'COVID-19 response in different communities within each county. However, this initial metric, while very useful, could be enhanced by including requirements for tracking and assessing adequacy of response to vulnerable populations such as farmworkers and, ideally, in sub-populations of farmworkers (e.g. indigenous-origin families, employees of farm labor contractors, women, middle-aged workers) [23].

Without expanded access to relevant and reliable statistical information, discussion among public offi- 
cials, agricultural employers, farmworker advocates, and service system providers such as primary health care providers, hospitals, and the public at large, about the spread of COVID-19 will inevitably be inadequate. The need for this range of organizations and the public to have broader access to reliable and a broader range of statistical data stems from the fact that organizations' decision-making as well as day-to-day public behavior rest to some extent on epidemiological evidence even in the face of widespread efforts to pit science against "common sense" and undermine trust in scientists and "doctors", i.e. epidemiologists. Transmission of information within social networks is known to have a particularly strong impact on attitudes, aspirations, and ultimately, behavior. Consequently, there are both immediate and long-term practical benefits in the battle against COVID-19 to having a broader and more accurate menu of analyses available to diverse audiences because behavioral decisions (by organizational players, informal influencers in social networks, and indviduals) are made continuously based on key audiences' ability to "digest" and consider the implications of statistical analyses and act on that information (e.g. awareness of nodes of transmission at super-spreader events, identification of geographic hot spots and relative risk of transmission in different physical contexts, prevalence of COVID-19 in different age cohorts).

Moreover, given the overall size of the farmworker population in the San Joaquin Valley region (about 300,000 farmworkers and 360,000 farmworker family members who make up about $15 \%-20 \%$ of the region's overall population) it is obvious that farmworkers' wellbeing in the face of COVID-19 must be of concern to the general public as well; there is inevitably diffusion of COVID-19 from "hot spots" to adjacent areas, through geographically widespread social networks and, among farmworkers and some other "essential" workers (e.g. truckers), mobility in moving from one place to another.

Effective response to COVID-19 spread needs to protect farmworkers and, just as importantly, their spouses, children, relatives, and others living in "joint dwellings" (the non-family members living "complex" households or compounds and sharing cooking facilities, bathrooms, and or sleeping space with a primary family). Due to the extent to which COVID-19 transmission takes place within crowded farmworker households [24], the farmworker family members who do not, themselves, work in the fields face risks quite similar to those farmworkers themselves confront.

Enhanced approaches to testing and contact-tracing in the San Joaquin Valley have potential for improved statistical reporting and more effective COVID-19 response in other farmworker areas of California. It can, therefore, benefit, all of the state's 1.8 million farmworkers and family members. Enhanced approaches implemented in California can also be adapted to assure the well-being of more than 4.2 million farmworkers and family members across the United States.

\section{What societal factors increase COVID-19 transmission in farmworker communities?}

"Societal factors" is meant to denote demographic, socioeconomic, sociopolitical, cultural, and community contextual factors, including built environment, that determine the $R_{t}$ of COVID-19 in a community - that is the real-time reproductive rate of the pandemic in a specific population living and working in a specific sociopolitical context [25].

There are several distinctive factors that make farmworkers even more vulnerable than other Latinos vis-àvis COVID-19 - both in terms of risk of infection and outcomes among those who are infected. Major factors include: poverty, employment in an essential industry, immigration status, lack of health insurance, and prevalence of crowded housing. These factors are co-variant in the California immigrant population but there has not been, to my knowledge, any comprehensive multivariate analysis of the overall correlation with risk of contracting COVID-19 or outcomes.

It must be recognized, also, that sociocultural factors such as literacy levels, most-utilized sources of health information, structuring of social networks, and modes of day-to-day interaction in community life have consequences for transmission.

Some of the principal factors which interact to make the population of farmworkers and their family members particularly vulnerable are. ${ }^{5}$

\subsection{Poverty}

Poverty is highly correlated with prevalence of COVID-19. The Los Angeles County Department of Public Health COVID-19 dashboard, a paradigm case of

\footnotetext{
${ }^{5}$ Data on national and California farmworker characteristics are drawn from tabulations of National Agricultural Worker Survey (NAWS) data from October 2015-September 2016. The NAWS does not currently survey guestworkers $(\mathrm{H}-2 \mathrm{~A})$ or workers in animal production, including dairy - but the profile of the livestock workers is similar to that of the seasonal agricultural services workers who are in the survey's sampling frame.
} 
thoughtful local government analysis and dissemination of COVID-19 statistical information, shows COVID19 to be more than twice as prevalent in high-poverty census tracts $(>29 \%$ HH's below poverty line) than in low-poverty tracts ( $<10 \%$ HH's in poverty) in the county. There was, for example, (as of September 11, 2020) a cumulative incidence of 3,743 cases $/ 100 \mathrm{~K}$ in the high-poverty areas of Los Angeles County vs. 1,447 cases/100K in the low-poverty areas [26]. These tracts also have very high proportions of Latino, Black, and Asian households but COVID-19 prevalence appears to be more directly correlated with household income, employment in an "essential" business where social distancing is difficult, and with crowded housing than with race/ethnicity.

Farmworker households, due as much to seasonal unemployment as to low wages, often live in poverty (with about $30 \%$ of households below the federal poverty level) and are further economically-burdened by the fact that eligibility for a broad range of social program support for low-income or otherwise disadvantaged households is conditioned on immigration status.

Although inter-state farmworker migrancy has been declining over the past decade, farmworkers'economic strategies continue to require a fair amount of intrastate migrancy which also may contribute to spread due to interfacing between separate local social networks. One of the most innovative recommendations, the Centers for Disease Control (CDC) has made to agricultural employers and workers is to strive to have work crews work in "pods" to minimize cross-network mingling and potential transmission [27], but the structure of the industry makes this difficult to implement. Almost half of California farm labor employment consists of workers employed by farm labor contractors or "custom harvesters" whose specific role is to move workers from one place to another as labor demand changes. Larger agricultural producers also often operate in multiple locations and move workers from one worksite to another.

\subsection{Employment in an essential industry}

Working in an "essential" occupation where social distancing is not easily achieved and is, at best, somewhat inconsistent, is another risk factor contributing to COVID-19 transmission and prevalence among farmworkers. There are now numerous news accounts and case studies indicating how the distinctive conditions of employment as a farmworker, which include transportation arrangements (in crowded cars, vans, or buses), close contact on work breaks due to lack of shade, and congregate housing for $\mathrm{H}-2 \mathrm{~A}$ guestworkers [28-32] lead to outbreaks. Much attention has been given to the very high risks of COVID-19 infection experienced by guestworkers but it is important to recognize that multiple factors contribute to COVID-19 spread in the farmworker population and that the impact of COVID-19 on local agricultural workers is also very high.

It is important to note here that U.S. agricultural producers' reliance on guestworkers - mostly Mexican workers admitted to work in U.S. agriculture under longstanding provisions in immigration law (commonly referred to as H-2A, the type visa issued to them) varies greatly from region to region in the country. Although the H-2A guestworkers make up only $10 \%$ of the U.S. farm labor force, their risk of COVID-19 infection is particularly high due to the Department of Labor's requirement that employers provide them with housing. In order to comply as cost-effectively as possible, almost all housing provided by employers is congregate housing - where, typically, a number of workers share bedrooms or sleep in barracks-style quarters, as well as sharing cooking facilities and bathrooms. California's reliance on guestworkers is lower than other major agricultural regions in the U.S. but there have been numerous reports of outbreaks in this sub-population in California agriculture [33].

Farmworkers are not alone in facing higher risks of SARS-CoV-2 infection due to work environment but, more than workers in many other essential industry sectors, they are confronted with employment conditions where employer compliance with a range of regulatory requirements, including those related specifically to COVID-19, varies greatly. The problems faced by farmworkers in the midst of the COVID-19 pandemic stem less from low earnings per se, than from uneven access to work-related benefits including sick leave, vacation leave, health insurance, other fringe benefits, and eligibility for government assistance.

Many reports have appeared documenting uneven efforts by agricultural employers to protect their labor force from worksite infection. Some have diligently sought to decrease transmission by instituting screening and social distancing measures recommended by the CDC, the California Department of Agriculture, the California Department of Labor and Workforce Development, and industry associations such as the Strawberry Commission and the California Farm Labor Contractors' Association. However, others have disregarded this advice and, more problematically, some have actively sought to suppress information about outbreaks of 
COVID-19 in their workforce from circulating among their workers or being revealed to the public.

Presumably, the riskiness of working in the essential industry of agriculture varies greatly from worksite to worksite and from one crop-task to another. There are no reports about COVID-19 transmission across the full spectrum of agricultural worksites but there are now extensive reports of outbreaks in packing sheds or other work contexts (such as field-packing of lettuce) where workers are lined up working with produce on conveyer belts. These specific working conditions are very risky since social distancing is difficult and aerosolization is probably a factor in transmission. However, there may be other "high traffic" nodes in field crop production that are especially problematic. In crops with piecerate-based pay, for example, workers rushing to dump buckets of produce in bins may have frequent close contact with the checkers who record their production. In a range of crop-tasks there is a lot of shouting. Access to hand-washing facilities is uneven. All of these factors provide opportunities for super-spreading.

\subsection{Immigration status}

More than half of California farmworkers (56\%) lack legal status. Lack of status contributes indirectly to increased transmission of COVID-19 due to undocumented workers' ineligibility for federal assistance to help out during time spent in isolation due to being infected or in quarantine due to being a close contact of an infected person. Experience to date has shown there is reluctance among undocumented farmworkers with only mild cases of COVID-19 to self-isolate and still more reluctance among asymptomatic close contacts of COVID-19 cases to self-quarantine, because those who lack legal status are ineligible for both unemployment insurance (UI) and CARES Act-funded pandemic assistance. General concern about "the government" using personal information for immigrant enforcement is also a powerful disincentive to securing testing.

The State of California has sought to address the problem of undocumented workers'exclusion from CARES Act assistance by setting up a state fund to provide assistance to households excluded from federal aid. But the initial funding (\$75 million from the state, matched with $\$ 50$ million from California philanthropy) was very rapidly exhausted [34] since there are about 1.75 million undocumented workers in California [35]. A number of streams of local philanthropic response have vigorously engaged in local fundraising to help address the problem of inequity due to immigration status and have made important contributions but the problem of economic pressures contributing to continuing work by COVID-19+ farmworkers persists and reluctance to seek testing continues to be a serious problem.

\subsection{Lack of health insurance and a "Medical Home"}

Agricultural employers are required to offer their permanent employees health insurance but this does little to help seasonal farmworkers and many low-income workers who often decline employers' offer of health insurance because co-payments are unaffordable for them and ACA-subsidized coverage is only available to those with legal status. Because farmworkers are economically-strapped almost half $(43 \%)$ lack health insurance and almost one-third (30\%) had not visited a U.S. health care provider during the 2 years before they were surveyed in NAWS [36].

\subsection{Crowded Housing: Large Families and "Joint Dwellings"}

One of the most distinctive and serious factors contributing to the prevalence of COVID-19 among farmworkers (and other low-income immigrants) is crowded housing where it is almost impossible for a COVID-19positive individual to self-isolate $[37,38]$. Research in a Latino immigrant neighborhood of San Francisco's Mission District from the University of California-San Francisco (UCSF), by relying on genotyping of the specificviral strains of infected individuals (an approach now being used more extensively in case investigation), provides a definitive demonstration of the extent of household transmission in crowded housing; $65 \%$ of COVID-19-positive individuals were infected with the same strain as their housemates [39].

NAWS data provide solid information on the proportion of farmworker housing that is crowded $(>1$ person/room) with $33 \%$ of farmworkers to be living in crowded housing in contrast to $2.4 \%$ of U.S. households [40]. And the farmworker households are larger averaging 5.1 persons/HH on the average vs. 2.7 person/HH for the average U.S. household.

In one of the major labor-intensive agriculture regions within California, the Salinas Valley, 93\% of farmworkers are living in crowded housing. There is, during harvest season, an average of 7.1 persons per household, and more than half $(54 \%)$ of the households are "joint dwellings", i.e. family members plus unrelated co-habitants [41]. This strategy of "doubling up" so as to be able to afford a place to live is ubiquitous in 
farmworker communities throughout the San Joaquin Valley and California. Research conducted in late 2018 throughout the San Joaquin Valley among Latino $1^{\text {st }}$ and $2^{\text {nd }}$ generation immigrants, many of whom are farmworkers, to assess the extent of differential census undercount in Census 2020, showed that about $20 \%$ lived in "complex households" (multiple families under one roof) or "complex compounds" (a primary housing unit with additional "unconventional" housing units at the address [42].

\subsection{Sociocultural factors}

The Mexican and Central American immigrants who make up the overwhelming majority of the U.S. farm labor force have constrained access to information on COVID-19 transmission and health consequences - because so many have very limited schooling and confront linguistic barriers to accessing the full range of information about COVID-19. Almost half of California farmworkers $(46 \%)$ have only attended elementary school while $42 \%$ read no English, and $27 \%$ have only limited English-language reading ability [36].

Basic information on COVID-19 is now widely available in Spanish and even in some of the main Mexican indigenous languages (Mixtec, Zapotec, Triqui) but the population is not very print-oriented. Nonetheless, word-of-mouth, outreach by community organizations, Spanish-language radio and TV coverage, have all attempted to promote the importance of wearing face covering, social distancing, and hand-washing but working/housing conditions still constrain behavior [43]. Farmworkers lacking information on health consequences of COVID-19 illness (omitted from the CDC basic "educational" materials) are likely to have attenuated awareness and aspirations about the utility of taking precautions to avoid COVID-19.

\section{Discerning patterns of COVID-19 impact in the farmworker population}

Generating insights about COVID-19 in the farmworker population by looking at farmworker communities is more useful than seeking to begin with improvements in enhancing data collection from individual cases. The reason is that collection of occupational data from individuals interviewed by contact-tracers is difficult and potentially misleading (especially for the most seasonal workers who may work in different jobs over the course of the year). At the same time, stan- dard North American Industrial Classification (NAICS) taxonomy of industry sub-sectors and Standard Occupational Classification System (SOC) taxonomy of occupations make it difficult for data analysts processing information from case tracing of COVID-19 cases to reliably code responses so that subsequent tabulation by occupation is seriously flawed. ${ }^{6}$

Community-level analysis aligns quite well with the actual risk factors experienced by farmworkers, because COVID-19 transmission is a two-way street where an infection contracted in the workplace is often transmitted to the home and vice versa. Transmission does differ in various "domains" of daytoday life of sub-groups in diverse communities but the reality is that these analytic "compartments" are permeable and, inevitably, linked. In farmworker communities, in-household transmission is likely to be extremely high, and thus heightens the linkage among the various domains where transmission can occur.

It is, possible to systematically identify farmworker communities using American Community Survey (ACS) data on local employment [44] and, then, by moving to tabulate prevalence and incidence of COVID-19. COVID-19 is routinely reported by zip code and easily linked to the ACS-derived detail on community characteristics. In addition to being practical, this approach reflects the epidemiological reality that although occupation is a significant risk factor for COVID-19, as a result of two-way transmission between worksite infection and within-household infection, farmworkers'household members are directly affected by the occupational risk of household breadwinner(s).

These community-level correlates of COVID-19 impact are documented in Table 1 showing the disparate impact of COVID-19 on farmworker communities in Fresno County and in Table 2 showing the disparate impact on farmworker communities in the Coachella Valley region of Riverside County, and in Table 3 showing disparities in farmworker communities in the Salinas Valley of Monterey County.

\footnotetext{
${ }^{6}$ Prevailing vernacular terminology referencing different types of agricultural production work do not align well with standard occupational classification that has not evolved to keep track with many ways in which production in the agricultural workplace has. The National Agricultural Worker survey codes respondents' reports about their work history with a cross-cutting system with a standardized inventory of crops and tasks that are then combined into a crop + task descriptor of each spell of employment.
} 
Table 1

Ratio of cumulative confirmed COVID-19 Cases/100K population in Fresno County farmworker towns to overall county and California (September 11-19, 2020)

\begin{tabular}{|c|c|c|c|c|c|c|c|}
\hline Column ref \# & 1 & 2 & 3 & 4 & 5 & 6 & 7 \\
\hline $\begin{array}{l}\text { TOWNS: \% farmworkers } \\
\text { Average household size }\end{array}$ & Population & $\begin{array}{l}\text { Cases per } 100 \mathrm{~K} \\
\text { in community }\end{array}$ & $\begin{array}{c}\text { Cases per } 100 \mathrm{~K} \\
\text { in county }\end{array}$ & $\begin{array}{c}\text { Community } \\
\text { to county ratio }\end{array}$ & $\begin{array}{l}\text { Community } \\
\text { to state ratio }\end{array}$ & $\begin{array}{c}\text { Testing } \\
\text { per } 100 \mathrm{~K}\end{array}$ & $\begin{array}{c}\text { Cumulative } \\
\text { \# of cases }\end{array}$ \\
\hline West Side sub-region & 91,768 & 4,041 & 2,602 & 1.7 & 2.2 & 17,614 & 3,709 \\
\hline $\begin{array}{l}\text { Cantua Creek } 63 \% \text { FW } \\
\text { HHsize }=3.2\end{array}$ & 940 & 3,830 & 2,602 & 1.5 & 2.0 & 16,054 & 36 \\
\hline $\begin{array}{l}\text { Tranquility } 54 \% \mathrm{FW}, \\
\text { HHsize }=3.3\end{array}$ & 1,173 & 2,813 & 2,602 & 1.1 & 1.5 & 12,276 & 33 \\
\hline $\begin{array}{l}\text { Huron } 53 \% \mathrm{FW}, \mathrm{HH} \text { size }= \\
4.0\end{array}$ & 7,260 & 5,207 & 2,602 & 2.0 & 2.7 & 14,132 & 378 \\
\hline $\begin{array}{l}\text { Mendota } 53 \% \mathrm{FW} \text {, HHsize } \\
=4.2\end{array}$ & 12,727 & 7,174 & 2,602 & 2.8 & 3.8 & 21,757 & 913 \\
\hline $\begin{array}{l}\text { San Joaquin } 45 \% \mathrm{FW}, \\
\mathrm{HHsiz}=3.8\end{array}$ & 4228 & 4,541 & 2,602 & 1.7 & 2.4 & 19,702 & 192 \\
\hline $\begin{array}{l}\text { Firebaugh } 36 \% \mathrm{FW}, \\
\text { HHsize }=3.8\end{array}$ & 10,395 & 3,127 & 2,602 & 1.2 & 1.6 & 11,236 & 325 \\
\hline $\begin{array}{l}\text { Laton } 30 \% \mathrm{FW}, \text { HHsize }= \\
3.6\end{array}$ & 3,541 & 3,361 & 2,602 & 1.3 & 1.7 & 15,250 & 119 \\
\hline $\begin{array}{l}\text { Raisin City } 23 \% \text { FW, } \\
\text { HHsize }=4.1\end{array}$ & 426 & 6,103 & 2,602 & 2.3 & 3.2 & 21,127 & 26 \\
\hline $\begin{array}{l}\text { Biola } 16 \% \text { FW, HHsize }= \\
4.4\end{array}$ & 949 & 5,901 & 2,602 & 2.3 & 3.1 & 19,705 & 56 \\
\hline $\begin{array}{l}\text { Riverdale } 33 \% \mathrm{FW}, \\
\text { HHsize }=3.9\end{array}$ & 6,323 & 3,701 & 2,602 & 1.4 & 2.1 & 12,668 & 234 \\
\hline $\begin{array}{l}\text { Caruthers } 24 \% \mathrm{FW}, \\
\text { HHsize }=3.6\end{array}$ & 5,586 & 4,368 & 2,602 & 1.7 & 2.3 & 14,680 & 244 \\
\hline $\begin{array}{l}\text { Kerman } 23 \% \text { FW, HHsize } \\
=3.8\end{array}$ & 20,195 & 3,773 & 2,602 & 1.5 & 2.0 & 13,459 & 762 \\
\hline $\begin{array}{l}\text { Coalinga } 12 \% \text { FW, HHsize } \\
=3.1\end{array}$ & 18,025 & 2,169 & 2,602 & 0.8 & 1.1 & 18,086 & 391 \\
\hline East Side sub-regions & 125,743 & 5,043 & 2,602 & 1.9 & 2.6 & 14,339 & 5,871 \\
\hline $\begin{array}{l}\text { Orange Cove } 46 \% \mathrm{FW}, \\
\text { HHsiz }=4.0\end{array}$ & 9,585 & 7,251 & 2,602 & 2.8 & 3.8 & 20,675 & 695 \\
\hline $\begin{array}{l}\text { Parlier } 35 \% \text { FW, HHsize } \\
=3.8\end{array}$ & 16,914 & 6,208 & 2,602 & 2.4 & 3.3 & 19,952 & 1,050 \\
\hline $\begin{array}{l}\text { Del Rey } 34 \% \text { FW, HHsize } \\
=3.8\end{array}$ & 2,664 & 4,279 & 2,602 & 1.6 & 2.3 & 14,865 & 114 \\
\hline $\begin{array}{l}\text { Reedley } 28 \% \text { FW, HHsize } \\
=3.5\end{array}$ & 30,935 & 4,238 & 2,602 & 1.6 & 2.2 & 16,573 & 1,311 \\
\hline $\begin{array}{l}\text { Sanger } 19 \% \mathrm{FW}, \text { HHsize } \\
=3.5\end{array}$ & 34,723 & 3,681 & 2,602 & 1.4 & 1.9 & 17,965 & 1,278 \\
\hline $\begin{array}{l}\text { Selma } 17 \%, \text { HHsize }=3.6 \\
\text { Comparison Areas }\end{array}$ & 30,922 & 4,602 & 2,602 & 1.8 & 2.4 & 18,608 & 1,423 \\
\hline $\begin{array}{l}\text { FW towns: av. } 28 \% \mathrm{FW}, \\
\text { HHsize }=3.8\end{array}$ & 217,511 & 4,420 & 2,602 & 1.7 & 2.2 & 16,747 & 9,824 \\
\hline $\begin{array}{l}\text { Fresno Co. } 10 \% \text { FW, } \\
\text { HHsize ïě̌=i̊ě } 3.2\end{array}$ & $1,010,120$ & 2,602 & 2,602 & - & 1.4 & 19,401 & 26,286 \\
\hline $\begin{array}{l}\text { California: } 2.3 \% \mathrm{FW}, \\
\text { HHsize }=3.0\end{array}$ & $39,780,000$ & 1,971 & - & - & - & 33,312 & 778,400 \\
\hline
\end{tabular}

Sources: Data on COVID-19 cumulative incidence of confirmed cases and community population from Fresno County COVID-19 dashboard on 9/11, California data from California Department of Public Health on 9/19. Community characteristics from US Census Bureau tabulation of ACS 2014-2018 data by city and census-designated place (CDP). \% FW in each community rounded to nearest whole percent, HHsize rounded to nearest $1 / 10^{\text {th }}$

\subsection{Fresno county farmworker towns}

Fresno County is the second largest county in the United States in numbers of farmworkers [45] and, has a relatively large number of easily-identified separate farmworker communities within this geographically large area $\left(15,570 \mathrm{~km}^{2}\right)$. Moreover, the farmworker population in the county is demographically and socioeconomically very similar to that of the entire Pacific Coast area of the United States (California, Oregon, and 


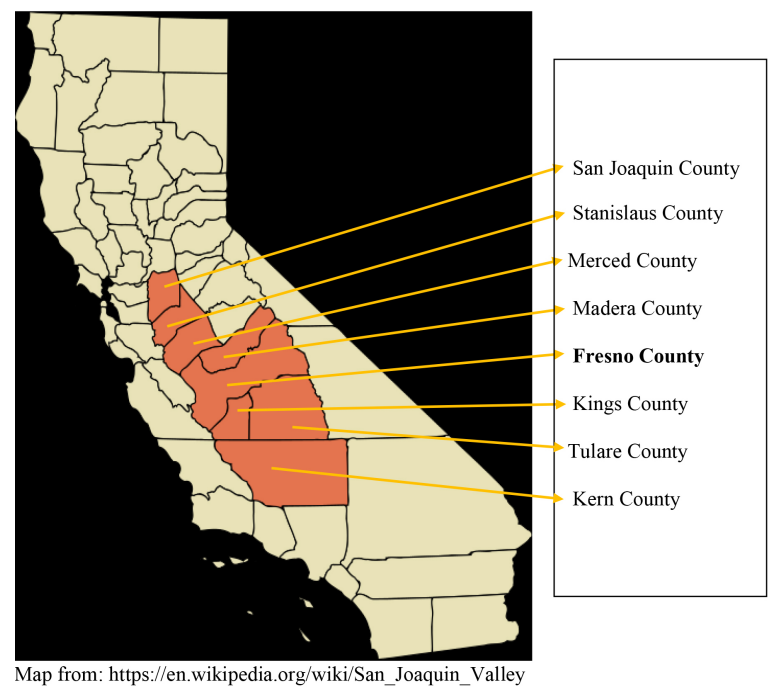

Fig. 1. Counties of the San Joaquin Valley, California.

Washington) where more than half of U.S. farmworkers live and work. Figure 1 shows the 8-county San Joaquin Valley region and Fresno County within the area.

The tabulations in Table 1 draw on widely-available data and are designed to be easily replicable and provide actionable insights of the magnitude of the disproportionate burden experienced by farmworking individuals and families in these communities, and to guide strategic response to COVID-19 based on the patterns that emerge from such tabulations.

Table 2 (for the Eastern Coachella Valley) and Table 3 (for the Salinas Valley) show how the approach can be customized to examine local patterns of COVID-19 prevalence in other California areas with concentrations of farmworkers. Both are major areas of labor-intensive agricultural production.

Comparing columns 2 and 3, Table 1 shows that the farmworker communities in Fresno County are disproportionately impacted by COVID-19. Even though Fresno County is a Latino-majority county (54\% Latino) and has a much higher cumulative incidence than the state as a whole (see 'Comparison Areas'in the table), farmworkers and their families are still more adversely impacted than the Latino population overall.

\subsection{Variations in prevalence of COVID-19 among Fresno County farmworker communities}

Although average household size is an imperfect indicator of household crowding, it accounts for a significant amount of variation in cumulative confirmed cases of COVID-19 within the stratum of farmworker communities $\left(r^{2}=0.544, p<0.000\right)$. Because ACS data is likely to under-report some of the most crowded households, the actual correlation between household crowdedness and prevalence of COVID-19 is likely to be still higher.

\subsubsection{Reliability of testing data in fresno county farmworker towns considering "density" of testing}

Fresno is currently the only county in the San Joaquin Valley region that reports level of testing by community; it will soon be required for all - a welcome development. Because the data reported in Table 1 show the cumulative number of COVID-19 tests/100K population in the farmworker towns, in the county, and in the state it is possible to calculate the ratio of "density" of testing in the farmworker towns as compared to the county and the state.

Over the course of the COVID-19 pandemic up through early September, density of testing in the Fresno County farmworker towns was at only $50 \%$ of the state level while testing in Fresno County overall was at $59 \%$ of the overall state level. Lower availability of testing increases the possibility that the reported data on positivity is not representative of the actual incidence in the overall population

The new California "Blueprint for a Safer Economy" formula for evaluating adequacy of county testing efforts is elegantly designed in that it creates a new indicator of COVID-19 prevalence (adjusted case rate) based on adjusting computation of the average number of confirmed new cases/100K population/week based on local "density" of testing (tests/100K population/week in relation to the state median level of testing). Therefore, as measured by the state indicator of "adjusted case rate" , testing at $50 \%$ the density of the overall state rate requires a correction factor of 1.2 to generate a derived estimate of actual detected cases.

\subsubsection{Adequacy of COVID-19 response in Fresno County farmworker towns based on the California indicator of positivity}

California state government expectations for positivity as a threshold for relaxing social distancing requirements is that adequacy of testing is related to \% of positive cases identified from all testing. High rates of positivity are considered to be indicators of inadequate control. Initial guidance from WHO provided a benchmark of $10 \%$ positivity in testing but expectations subsequently increased. As of September $23^{\text {rd }}$, California sought to get counties to achieve a testing positivity rate 
Table 2

Ratio of COVID-19 cases in Eastern Coachella Valley Farmworker towns to county and state September 11-16, 2020

\begin{tabular}{|c|c|c|c|c|c|c|}
\hline Column ref \# & 1 & 2 & 3 & 4 & 5 & 6 \\
\hline Community & Population & $\begin{array}{l}\text { Confirmed } \\
\text { cases }\end{array}$ & $\begin{array}{c}\text { Cases } \\
\text { Per } 100 \mathrm{~K}\end{array}$ & $\begin{array}{l}\text { Community to } \\
\text { county ratio }\end{array}$ & $\begin{array}{l}\text { Community to } \\
\text { state ratio }\end{array}$ & $\begin{array}{l}\text { Testing } \\
\text { per } 100 \mathrm{~K}\end{array}$ \\
\hline Oasis $68 \%$ FW HHsize $=2.9$ & 3,020 & 313 & 10,364 & 4.9 & 5.8 & 42,400 \\
\hline Mecca $41 \%$ FW HHsize $=3.7$ & 7,174 & 416 & 5,799 & 2.8 & 3.3 & 23,500 \\
\hline Thermal $18 \%$ FW HHsize $=2.9$ & 1,359 & 161 & 11,847 & 6.7 & 6.7 & N/A \\
\hline North Shore $23 \%$ FW HHsize $=3.2$ & 2,892 & 122 & 4,219 & 2.0 & 2.4 & 18,200 \\
\hline Small, predominantly $\mathrm{FW}$ communities & 14,445 & 1,012 & 7,006 & 3.3 & 3.9 & 28,033 \\
\hline Coachella $20 \%$ FW, HHsize $=3.1$ & 46,813 & 2,507 & 5,355 & 2.5 & 3.0 & 26,600 \\
\hline Indio $11 \% \mathrm{FW}, \mathrm{HH}$ size $=3.1[100 \mathrm{j}]$ & 93,738 & 3,440 & 3,670 & 1.7 & 2.1 & 24,500 \\
\hline $\begin{array}{l}\text { Urbanized communities w/ some farmwork- } \\
\text { ers }\end{array}$ & 140,551 & 5,947 & 4,231 & 2.0 & 2.4 & 25,550 \\
\hline Riverside Co. $1.5 \%$ FW HHsize $=3.3$ & $2,517,830$ & 52,909 & 2,101 & & & 16,400 \\
\hline State of CA $2.3 \%$ FW, HHsize $=3.0$ & $39,780,000$ & 707,896 & 1,779 & & & 33,312 \\
\hline
\end{tabular}

* 2018 research by the author $[100 \mathrm{~g}]$ suggests there is a significant underrepresentation of the farmworker population in Mecca (in the range of $5 \%-8 \%$ ) due to census omission of "low visibility/hidden" housing units[100i]. There are likely to be similar biases in census data for the other farmworker communities in the area. As a result of undercounting the farmworker population, household size in the farmworker communities is almost certainly larger than reported and proportion of farmworkers higher than reported in the American Community Survey data. Data on testing per $100 \mathrm{~K}$ population for Riverside County is from 9/16/20 and for California from 9/11/20.

of $<2 \%$ to be designated as an area with "minimal" COVID-19 prevalence.

On September 30 ${ }^{\text {th }}$, Fresno County's COVID-19 dashboard data showed that the cumulative COVID-19 positivity rate in the county over the course of the pandemic, i.e. total tests/total positive, was $9.8 \%$ - slightly better than the original WHO benchmark but (along with most California counties) below the state's current goals. However, there was a cumulative positivity rate of $26.4 \%$ for the farmworker towns - about two-anda half times the cumulative county-wide rate. Tabulations during the first month of such reporting (October) show the utility of these indicators as input for strategic decision-making.

The good news is that substantial improvements are indicated in overall testing in Fresno County as indicated by the indicator of current positivity among tests; by the week of September $11^{\text {th }}$, the California state tabulations show a testing positivity rate of $4.9 \%$ for Fresno County and an unadjusted case rate of 6.1 new cases/100K population/week [47].

\subsection{Eastern Coachella Valley farmworker towns}

The Eastern Coachella Valley is a small sub-county area in Riverside County with intensive agricultural production and dense settlement of immigrant farmworkers. The places and cities identified as farmworker communities in the area include four small self-contained communities and two larger cities that were originally farmworker settlements but that have now grown and diversified. There are also scattered clusters of small trailer parks where farmworkers live. Analysis of the cu- mulative incidence of COVID-19 in the six farmworker communities in the Eastern Coachella Valley agricultural region of Riverside County in southern California shows the farmworker communities in this distinctive sub-region to have even more extensive COVID19 spread: 2.0 to 6.7 times the cumulative incidence of COVID-19 of that reported for the overall county (columns 4 and 5). Table 2 above shows the observed pattern.

\subsubsection{Adequacy of testing and strategic response to COVID-19 in the coachella valley}

As in the case of the Fresno County farmworker communities, it can be seen that, despite vigorous efforts to improve testing access there has been less testing per $100 \mathrm{~K}$ population in the farmworker area of Riverside County as compared to the state. Based on the cumulative data, the "density" of COVID-19 testing as of September 16 was slightly over $75 \%$ of the level achieved by the state. Cumulative testing positivity was at about $25 \%$ for the smaller, predominantly farmworker, communities and about $16 \%$ for the larger communities with a significant farmworker population but a broader occupational mix.

Within the state framework, the density of local testing, while somewhat lower than the state average, would be considered adequate and no case adjustment would be required. Notwithstanding, it should be noted that the average level of positivity is still high. As in Fresno County, in the Eastern Coachella Valley there is now progress in making testing more easily available, so that the current positivity rate was $4.8 \%$ for the week of September 23 - i.e. diminishing. 


\subsection{Salinas Valley farmworker towns - and the role crowded housing plays in COVID-19 transmission}

Often called the "Salad Bowl of the World", Monterey County's farmworker communities - part of the Salinas Valley - have experienced spikes in COVID19 like the other communities just discussed. Here, however, there is additional evidence of the ways in which farmworker housing conditions contribute to COVID-19 spread within the Salinas Valley of Monterey County. This evidence stems from the availability of high-quality detailed data on farmworker housing generated by farmworker researcher, Richard Mines as part of his 2018 farmworker survey conducted for the Salinas Pajaro Valley Agricultural Worker Housing Survey [46]. Mines defines "joint dwellings" as housing shared by multiple households - a primary family household head by a homeowner or principal renter and "extra" people sharing space. The detailed data collected in Mines'study includes details about housing conditions among farmworkers and their families specifically - that provide valuable insights into the ways in which these sorts of living conditions affect COVID-19 transmission. The report summarizes farmworker housing conditions as follows:

Most farmworkers live with others (largely other farmworkers) who are outside their family budgetary unit. Non-related adult men and women, and non-related families were all common "joint tenants". For the entire set of dwellings, the "extra" residents add an average of 3.2 people per dwelling. Overall, the residences averaged over 7 people per dwelling when both family and "joint" residents were combined.

Sometimes, owners or renters will rent out one or more of the rooms (or other spaces) in their house or apartment. Twenty-eight percent of owners and $18 \%$ of renters rent or sublease to joint dwellers. Many people were reported as sleeping outside of bedrooms, of these $79 \%$ were adults and $21 \%$ were children. Most of these non-bedroom sleepers take their rest in the living room or the garage. (page 143, Salinas Pajaro Agricultural Worker Housing Survey).

Mines reports that $15 \%$ of the farmworkers surveyed did not have a bedroom to sleep in and slept in a kitchen or a hallway. Crowdedness also resulted in more than 5 people per bathroom - both in cases where everyone lived under the same roof and in cases where people housed in a garage or backyard trailer shared a bath- room with the householder and primary family in "the main house". More than one-third of the households (39\%) had extreme crowding -2 or more persons per room.

Table 3 provides additional evidence of the burden of COVID-19 in farmworker communities but adds to the analysis by directly demonstrating the role that crowded housing plays in the spread of the virus.

When looking at spatial patterns of COVID-19 prevalence in the Salinas Valley, the relationship between housing conditions and COVID-19 becomes even more dramatic than in the analyses of the evidence from Fresno County and the Eastern Coachella Valley and yet again shows the disproportionate impact the pandemic is having on farmworkers, their families, and their communities. More than three-quarters of Monterey county's COVID-19 cases are in the Salinas Valley farmworker communities identified below in Table 3 . Although the impact of COVID-19 varies throughout the area it is consistently higher in the farmworker communities and in neighborhoods with a higher proportion of overcrowded joint housing.

Table 3 shows that relative crowdedness of housing is related to prevalence of COVID-19 providing additional evidence that within-household transmission is a major factor in spread. ${ }^{7}$

\section{What Next? - Improving local statistical reporting on the impact of COVID-19 on farmworkers}

The State of California has attempted to address an important shortcoming of county-level reporting on COVID-19 impact - the problem of uneven levels of testing in some counties - by incentivizing county public health system efforts to increase testing rate. State approval of county plans for "opening up" their economy, moving up in tiers of increasingly relaxed social distancing regulations for businesses, is based on metrics showing that counties are conducting adequate

\footnotetext{
${ }^{7}$ In addition to extremely crowded housing, Mines' analysis of data from the recent California Institute of Rural Studies' COVID-19 Agricultural Worker Study shows that the Salinas Valley area has a higher proportion of indigenous-origin farmworkers than in the inland areas of the San Joaquin Valley and the Eastern Coachella Valley (Richard Mines, personal communication, October 10, 2020). This is a reminder of the sociocultural factors mentioned earlier - that language ability, poverty, low educational attainment may be important factors too - since the indigenous-origin population is socially, economically, and culturally disadvantaged in all these respects.
} 
Table 3

Variations in cumulative incidence of COVID-19 in the Salinas Valley in relation to prevalence of joint housing

\begin{tabular}{lccccc}
\hline $\begin{array}{l}\text { Salinas Valley community and } \\
\text { neighborhood }\end{array}$ & Population & $\begin{array}{c}\text { \# COVID-19 } \\
\text { Cases 9-24-20 }\end{array}$ & $\begin{array}{c}\text { \% joint } \\
\text { dwellings }\end{array}$ & $\begin{array}{c}\text { Cumulative cases } \\
\text { per 100K pop. }\end{array}$ & $\begin{array}{c}\text { Ratio of community } \\
\text { to county }\end{array}$ \\
\hline Greenfield 93927 & 16,398 & 847 & $68 \%$ & 5,165 & 2.3 \\
Salinas Southeast 93905 & 61,087 & 2,600 & $63 \%$ & 4,256 & 1.9 \\
King City 93930 & 16,638 & 655 & $47 \%$ & 3,937 & 1.8 \\
Soledad 93960 & 19,391 & 874 & $46 \%$ & 4,507 & 2.0 \\
Chualar 93925 & 1,913 & 68 & $33 \%$ & 3,555 & 1.6 \\
Gonzalez 93926 & 8,306 & 290 & $30 \%$ & 3,491 & 1.6 \\
Salinas Northeast 93906 & 59,461 & 1,950 & $27 \%$ & 3,279 & 1.5 \\
Salinas Valley FW survey & 183,194 & 7,284 & $53 \%$ & 3,980 & 1.8 \\
Total-Monterey Co. & 435,828 & 9,772 & N/A & 2,242 & \\
\hline
\end{tabular}

* Tabulation only includes communities where cell sizes of Pajaro-Salinas Valley Farmworker Survey data make it possible to reliably estimate the proportion of joint housing. Farmworker neighborhoods and communities not included in the tabulation due to small cell size ( $<10$ cases) are Freedom, Spreckels, and Salinas zipcodes 91733, 92901, 92905, 93901, 92905, 93901, and 95093.

COVID-19 testing based on a formula incorporating positivity rate among tests reported adjusted by adequacy of local tests/100K population as compared to overall testing in the state [47].

This policy provides a good example of commitment to strategic decision-making based on systematic analysis of easily-available statistical information. But further progress will be needed - both in developing metrics that encourage more granular analysis of transmission patterns and in improving representativeness of testing data collected and reported.

What next? More attention needs to be paid to farmworker communities - attention that contributes to informed decision making, program design, interaction with the people in the communities, and assessment of progress. As can be seen from the preceding analysis, it is possible to "zoom in" on these populations of interest, if it is considered necessary and useful to do so. Both a failure of political will and failures in reporting design and collection methodologies account for the current lack of focus.

Statistical reporting on COVID-19 among farmworkers and other high-risk populations needs to be seen in the context of the national reporting system and overall strategy of targeted response to counter pandemic spread - in high-risk groups and in geographic areas where surges are observed. Targeting strategy is now being addressed in national planning for a vaccination campaign but it will be important to remember that, for many months after a vaccine becomes available, non-pharmaceutical interventions will necessarily continue to be a major weapon in fight against the pandemic and that enhanced statistical reporting will be a key underpinning in making that mode of response effective.

The indicator I focus on here, cumulative incidence of confirmed cases, is an imperfect indicator of the full impact of COVID-19 in any community because such a high proportion of cases are asymptomatic and because current incidence of new cases better reflects the situation at discrete points in time. Nonetheless, it is likely that "hotspots" of COVID-19 spread identified on the basis of cumulative incidence will continue to be relevant to analysis because models" "nowcast" estimates of $R_{\text {eff }}$ have limited geographic resolution and continue to fluctuate due to the noisiness of short-term detection (weekly incidence of new cases) in small areas (e.g. census tracts, communities, neighborhoods with a population of $<10,000)$.

\section{County COVID-19 dashboards: Public access to information to shape community-level behavior and strategic response}

Johns Hopkins University developed the first COVID-19 dashboard to provide online COVID-19 reporting to the public. It was first shared publicly on January 22, and subsequently reported February 19 in The Lancet [48]. This provided an initial, thoughtfullyconfigured, template for national reporting. The template was also made available to local public health departments and was soon adopted by many. COVID-19 dashboards came to be the primary approach to disseminating local information on the pandemic to the public and stakeholders. Although the traditional approach of holding periodic press conferences to disseminate summary information continued in parallel in some places, the dashboards appear to have been, from the beginning, the primary vehicle for sharing statistical information on the COVID-19 pandemic.

The importance of effectively communicating statistical information on COVID-19 to the public stems 
from two distinctive features of the SARS-CoV-2 virus. The first consideration is that, due to its "novelty" as a human pathogen and absence of pre-existing immunity, it is clear that, for an extended period of time, "non-pharmaceutical interventions" - messaging and government actions to influence social behavior - will be critical.

The second consideration is that the virus' intrinsic reproductive factor $\left(R_{0}\right)$ is high enough that there can be exponential spread - "explosions" of COVID-19 out of "hotspots" and that $R_{t}$ may, in some identifiable populations and identifiable sociocultural contexts and types of built environment, be much higher than others. Confronted with this challenge, detection of hotspots and public communication tailored to diverse situations needs to play a major role in strategic response to the disease. Detailed geographic depiction of patterns of spread is therefore necessarily part of the narrative to better inform people about their immediate situation in the communities where they live and work.

\section{Principles for standardized reporting on key aspects of pandemic spread and system response}

From the beginning, the counties' COVID-19 dashboards reported several standard epidemiological indicators: cumulative incidence of confirmed cases, new cases in past week, in a 2-week look back period, hospitalizations, and deaths. However, by the end of April, 2020, despite President Trump's announcement that social distancing initiatives could be relaxed "by Easter", as the initial surge of COVID-19 peaked and first began to subside, a high-level framework of metrics for evidence-based strategic response to the pandemic was proposed as part of national discussion of evidencebased decisions about "opening up", conditions for relaxing social distancing [49]. However, although the task force that developed the metrics was led by former Federal Drug Administration (FDA) Commissioner Scott Gottlieb, the proposed framework for evidencebased "opening up" became controversial and was never adopted.

Then, in July, 2020, a comprehensive and reflective assessment of national reporting required for optimal pandemic strategic response was published by Resolve To Save Lives, a prominent organization headed by former CDC Director Thomas Friedan [50]. This analysis was not specifically about local COVID-19 dashboards but had direct relevance since it put forward recom- mendations for overall metrics in analysis and reporting of epidemiological data. Major issues identified in the report included lack of uniformity in tabulations, the need for more granularity in reporting, and indicators for assessing public health system performance. The COVID-19 reporting constraints highlighted in the report are evident not only in examining inter-state variations but also in the intra-state statistical "feeder system" of county-level reporting in California and most other states.

\section{Where we are at now - as of November 2020 - local public health system generation and dissemination of statistical information on COVID-19}

Local-level statistical reporting, within the United States, and internationally, can contribute to or distract from efforts to work more strategically to reduce health disparities affecting vulnerable populations. In the current $21^{\text {st }}$ century context, the abstract ideal of epidemiological professionalism in decisions about information dissemination needs to be nurtured with efforts to enhance appreciation of the ways in which effective communication can help or hinder civic engagement and public behavior.

Although the San Joaquin Valley region of California is a major "hot spot" for COVID-19, county COVID-19 dashboards do not yet provide the general public, local stakeholders, public officials, and organizations with adequate information to have the required impact on public attitudes, aspirations, and behavior - the factors which are actually the key determinants of transmission.

As we move into the winter 2020-2021 flu season, as "lockdown fatigue" increases, and the public grows wary of constant re-framing and revision of COVID-19 "facts" and issues - we really need to improve the use of statistical information as a tool for positively impacting public behavior - including sub-population such as farmworkers. It should be appreciated that sound and systematic statistical reporting can play an important role in improving currently uneven public compliance with measures to reduce transmission. The San Joaquin Valley public health departments have made gestures in that direction, but effectiveness of communication varies greatly from county to county.

In particular, published statistical tabulations should, as part of reporting on patterns of COVID-19 prevalence, incidence, and trends, be adequate to allow stakeholders and the public (especially particularly vulnera- 
ble groups such as nursing home residents, and different high-risk occupational groups such as farmworkers and frontline responders) better understand the distinctive infection risks they and their families face.

Statistical reporting, in addition to tracking the course of the pandemic, also needs to provide a basis for assessing the adequacy of public health system performance in confronting COVID-19. Transparency in reporting about the spread of COVID-19 is needed but, just as importantly, information is needed about steps taken by the public health system to confront the pandemic and how successful those efforts have been in order to assure accountability of the public health system.

In the San Joaquin Valley region where fiscal conservatism dampens local government commitment to making necessary investments in public health interventions to combat COVID-19 it is necessary to give special attention to provisions which make it possible to monitor and evaluate system performance in responding to it and, on that basis, advocate for necessary changes in strategy and/or implementation of response measures. The sociopolitical dynamics relating to official statistical reporting on COVID-19 in the San Joaquin Valley are akin to those that will need to be confronted internationally, especially in countries where public sector concerns about the economic consequences of social distancing mandates detract from attention to public health dimensions of the pandemic.

For example, in Fresno County, officials deferred allocating \$29 million of federal CARES Act funding earmarked for emergency response to the COVID-19 pandemic in the hope that their lobbyists could make Congress change federal law to allow the definition of "COVID-19 emergency" to be expanded to include the negative fiscal impacts that state "shelter in place" regulations had on county government revenue from sales tax [51]. However, by late summer, as a result of external pressure, county local government approved promising partnerships between the public health department and community health centers to expand availability of free testing, complemented with efforts by trusted community-based organizations working in different ethnic communities to promote testing and support contact-tracing.

It is unfortunate, there was delay in taking these very practical steps, but, once implemented, they have the potential to increase the effectiveness of efforts to curb COVID-19 transmission and improve statistical reporting. There are, however, many uncertainties, about the extent to which they will significantly impact COVID19 prevalence. If, as some models project and as Oc- tober data suggest, incidence of COVID-19 ramps up faster than effective contact-tracing can be conducted and proactive isolation efforts are put in place, the impact of this promising model may be minimal.

Table 4 below summarizes the current status of local county COVID-19 dashboards in October, 2020seven months after the dashboard were instituted. The indicators included in the table draw on Resolve to Save Lives'indicators needed for national response to the COVID-19 pandemic. They are somewhat scaleddown from the national recommendations to a level that would seem more appropriate for statistical reporting by local government entities.

The reporting and presentation of information on the county dashboards has improved greatly over the eight months since the pandemic first emerged in the region. For example, Fresno County's COVID19 dashboard that had early on reported cumulative incidence of cases $/ 100 \mathrm{~K}$ population now also includes a community-by-community indicator of testing adequacy (tests/100K population). Merced County's COVID-19 dashboard, now includes a line graph of cumulative cases that usefully shows the changing slope of increase in cases in different communities.

Yet, at the same time, the divergence in local presentations as each county pursues its own reporting trajectory reflects different priorities about the information that deserves to be made public without any consistency in visualizing how public dissemination of statistical information might make the most practical contributions to strategic response. Despite the amount of data that is included on each dashboard, there is little evidence of careful consideration or inter-county coordination about what sorts of tabulations or presentations might best support sound decision-making by the diverse audiences who need it - e.g. public officials, partnering local organizations, different segments of the public, etc. Parents of school-age children, as well as the K-12 school system, might be interested in prevalence among children 5-18 years old. Agricultural employers might be interested in prevalence in the farm labor force. However, these "user-oriented" statistical analyses, even those that require only straightforward cross-tabulation, are not available.

\section{Improving the utility of COVID-19 data reported by county public health departments}

Improving public health system performance requires both improvements in reporting and in data quality. The 
Table 4

San Joaquin Valley published tabulations of key epidemiological data on county COVID-19 dashboards

\begin{tabular}{|c|c|c|c|c|c|c|c|c|c|c|c|c|c|c|c|c|}
\hline \multirow{2}{*}{$\begin{array}{l}\text { Key county-level indicators } \\
\mathrm{B}=\text { Basic county-level tabulation } \mathrm{X}= \\
\text { Xtab X age, sex, race/ethnicity, comorbidi- } \\
\text { ties }\end{array}$} & \multicolumn{2}{|c|}{ Fresno } & \multicolumn{2}{|c|}{ Kern } & \multicolumn{2}{|c|}{ Kings } & \multicolumn{2}{|c|}{ Madera } & \multicolumn{2}{|c|}{ Merced } & \multicolumn{2}{|c|}{ San Joaquin } & \multicolumn{2}{|c|}{ Stanislaus } & \multicolumn{2}{|c|}{ Tulare } \\
\hline & $\mathrm{B}$ & $\mathrm{X}$ & B & $\mathrm{X}$ & B & $\mathrm{X}$ & $\mathrm{B}$ & $\mathrm{X}$ & B & $\mathrm{X}$ & $\mathrm{B}$ & $\mathrm{X}$ & $\mathrm{B}$ & $X$ & $\mathrm{~B}$ & $\mathrm{X}$ \\
\hline 1. Cumulative cases/100K population & $\mathrm{X}$ & $\mathrm{X}$ & $\mathrm{X}$ & $\mathrm{X}$ & $\mathrm{X}$ & $\mathrm{X}$ & $\mathrm{X}$ & $\mathrm{X}$ & $\mathrm{X}$ & $\mathrm{X}$ & $\mathrm{X}$ & $\mathrm{X}$ & $\mathrm{X}$ & $\mathrm{X}$ & $\mathrm{X}$ & $\mathrm{X}$ \\
\hline 2. Incidence-new cases/day & $\mathrm{X}$ & - & $\mathrm{X}$ & - & $\mathrm{X}$ & - & $\mathrm{X}$ & - & $\mathrm{X}$ & - & $\mathrm{X}$ & - & $\mathrm{X}$ & - & $\mathrm{X}$ & - \\
\hline 3. $\%$ of tests positive & $\mathrm{X}$ & - & $\mathrm{X}$ & - & $\mathrm{X}$ & - & $\mathrm{X}$ & - & $\mathrm{X}$ & - & $\mathrm{X}$ & - & $\mathrm{X}$ & - & $\mathrm{X}$ & - \\
\hline 4. Tests/100K pop & $\mathrm{X}$ & - & - & - & - & - & - & - & - & - & - & - & - & - & - & - \\
\hline 5. Deaths & $X$ & $\mathrm{X}$ & $\mathrm{X}$ & $\mathrm{X}$ & $\mathrm{X}$ & $\mathrm{X}$ & $\mathrm{X}$ & - & $\mathrm{X}$ & - & $\mathrm{X}$ & $\mathrm{X}$ & $\mathrm{X}$ & $\mathrm{X}$ & $\mathrm{X}$ & $\mathrm{X}$ \\
\hline 6. Hospitalizations & $\mathrm{X}$ & - & $\mathrm{X}$ & - & $\mathrm{X}$ & - & - & - & $\mathrm{X}$ & - & - & - & $\mathrm{X}$ & $X$ & $\mathrm{X}$ & $\mathrm{X}$ \\
\hline $\begin{array}{l}7 \text { Outbreaks: living facilities and essential } \\
\text { workplaces }\end{array}$ & - & - & - & - & - & - & - & - & $X$ & - & - & - & - & - & - & - \\
\hline $\begin{array}{l}\text { 8. Time from seeking testing to securing a } \\
\text { test }\end{array}$ & - & - & - & - & - & - & - & - & - & - & - & - & - & - & - & - \\
\hline $\begin{array}{l}\text { 9. Time from testing to isolation of cases, } \\
\text { by week }\end{array}$ & - & - & - & - & - & - & - & - & - & - & - & - & - & - & - & - \\
\hline $\begin{array}{l}\text { 10. \% cases interviewed for contact elicita- } \\
\text { tion w/in } 48 \text { hours of specimen collection } \\
11 . \% \text { of contacts identified by cases con- } \\
\text { tacted within } 48 \text { hours }\end{array}$ & - & - & - & - & - & - & - & - & - & - & - & - & - & - & - & - \\
\hline 12. $\%$ of new cases linked to other cases & - & - & - & - & - & - & - & - & - & - & - & - & - & - & - & - \\
\hline $\begin{array}{l}\text { 13. \% of new cases among quarantined } \\
\text { contacts, by week }\end{array}$ & - & - & - & - & - & - & - & - & - & - & - & - & - & - & - & - \\
\hline
\end{tabular}

*Indicators 3 and 4 were included in the California Department of Public Health framework, "Blueprint for a Safer Economy" regulations issued September 23 so that counties are transitioning to diligently reporting them since there is avid public interest in counties'progress through the state's tiers of increasingly relaxed social distancing as local progress is made in decreasing COVID-19 transmission.

summary review of current reporting available on counties' COVID-19 dashboard in Table 4 provides a framework for considering what improvements in reporting might be needed to nurture more extensive and thoughtful public engagement. I discuss these improvements first and then go on to discuss ways to improve data quality.

\subsection{Tabulation of COVID-19 patterns}

Important improvements in public health system reporting to the public on COVID-19 prevalence, incidence, and transmission patterns include the following.

\subsubsection{Need for "Normalized" tabulations of data to facilitate interpretation and comparison}

Reporting needs to be crafted to give more attention to how mode of a presentation can inform the beliefs, attitudes, aspirations, and behaviors of key information stakeholders - how information shared with the public can provide the most relevant information for interpreting "how it's going" and "what to do".

Most of the county COVID-19 dashboard report cumulative incidence of cases by community/zipcode but present only the raw number of cases without normalization. This makes community-to-community compar- isons and visualization of patterns of COVID-19 spread very difficult for the average information-seeker.

Then, there are also different visualizations of key metrics. Fresno County, for example, conforms to national and state practice in reporting cumulative incidence of cases/100K population but Merced County reports cumulative incidence of cases as a "per capita" number that actually reflects \# of cases $/ 1 \mathrm{~K}$ population because the department believes it is "easier for the public to understand". Although this idiosyncratic decision was a reasonably-considered one, it also creates confusion when comparing the local situation to other counties, the state, or the nation.

If all the counties in the region were to take the simple step forward of publishing normalized tabulations for key variables, the data would be easier to quickly and accurately digest and county-to-county comparisons would be possible. On some of the dashboards, for example the standardized rate of increase in new cases is currently represented in a fairly accessible way via line graphs of new cases/day showing slope/rate of increase; but this tacitly implies that "eyeballing" the rate is all that's needed so the lack of precise numerical data fosters drawing fuzzy conclusions.

\subsubsection{Need for improved categorization to make reporting on "source of exposure" useful}

Standard categorization of "source of exposure" of 
COVID-19 cases provides minimal actionable information due to the breadth of the categories in which the data are grouped: "close contact", "travel", "community spread/unknown". This broadly-defined traditional categorization of source of exposure provides little information useful for guiding personal or program and intervention decision making vis-à-vis COVID-19.

Consigning a wide range of exposures into reporting on "community spread" provides no useful information. In Fresno County, $56.5 \%$ of all cases are currently categorized as "unknown or community spread". Although this is transparent reporting of the data obtained, it is, at the same time, an admission that contact tracing has not worked well in the county. ${ }^{8}$ Meanwhile the remaining "source of infection" categories reported (40\% as "close contact" and $2.2 \%$ as "travel") are so generic they also cannot be used as the basis for tailoring improved interventions, and do not provide the public actionable information to spur behavioral change.

From a strategic perspective, the conceptual geography used in categorizing "source of contact" is most useful if it is aligned with a taxonomy of different types of physical environments relevant to the mode of transmission of each specific disease. Four broad domains identified in the epidemiological literature include: workplace, school, home, and "community" (basically all other social interactions) and can be used to construct an optimal reporting framework for the specific modes of transmission of SARS-CoV-2. For example, sub-categorization of "home environments" to distinguish congregate living situations as distinct from typical family housing, and, within congregate living settings, further sub-categorization of prisons, nursing homes, $\mathrm{H}-2 \mathrm{~A}$ housing provided by employers to guestworkers would all be practically useful in guiding response and be responsive to the local audiences' interest. For example, tabulation of COVID-19 cases believed to stem from school environment would be likely to interest many in the general public and be useful - but such reporting is not yet available.

In the current strategic context, where there is a need to explore hypotheses about COVID-19 transmission in high-risk populations such as the farmworker population and use findings as a basis for developing tailored interventions, it would be very useful to adopt

\footnotetext{
${ }^{8}$ Fresno County is not unique in this regard. High proportions of cases classified as "unknown" or "community spread" are common throughout the state and the nation. It reflects widespread failures of contact-tracing that are well documented on a listserve maintained by the National Institute of Health's Fogarty International Center.
}

an analytic taxonomy for epidemiological reporting in the San Joaquin Valley that includes categorization of "source of transmission" into environments where targeted strategies could be put in place:

- workplace (with sub-categories of indoor environment, outdoor environment, and transportation to/from work), eventually, perhaps even crop-task

- home (with sub-categories of crowded living quarters in standard household of 1 family/housing unit, crowded living quarters in complex households with multiple family/social units under the same roof, and congregate employer-provided housing)

- schools (possibly sub-categorized as pre-school, K-6, Middle School, High School). The absence of any cases reported as stemming from transmission in schools is very surprising.

- community (possibly categorized as community celebration, sporting event, visit to retail establishment, visit to restaurant, visit to bar, etc.)

Providing more detailed categorization of source of exposure would meet the twin objectives of informing program designers, analysts and evaluators of the success of their interventions and identifying areas where tweaks may be needed; at the same time, it would better inform the public about how their behavior has protected them (or failed to protect them) and others. Tailoring local reporting to distinctive local context, does not obviate standardized reporting within the state and national public health system. ${ }^{9}$

There remain serious challenges in carrying out both standard "forward" contact-tracing and "backward" contact-tracing to identify source of exposure although some experts recommend "backward" contact tracing as a valuable tool for COVID-19 suppression since a good deal of transmission is from "super-spreader" events and environments. In some cases it will be impossible, even with high-quality case investigation and contact-tracing, to determine source of exposure. However, acknowledging this "healthy" uncertainty rather than pooling all case investigation failures into an "unknown" category will improve precision of reporting.

\footnotetext{
${ }^{9}$ In California, local reporting on COVID-19 is actually a hybrid data system where COVID-19 test data is drawn from the state's standard electronic system for epidemiological reporting (Cal-REDIE) while additional contact-tracing information is generated by the counties. The state is now transitioning to a new electronic reporting system specifically for COVID-19. However, national and state reporting guidelines may turn out to be problematic as testing technology evolves because antigen test findings are currently not considered to be "confirmation" of COVID-19 positivity and are not included in tallies even as local utilization of this testing technology increases.
} 


\subsubsection{Need for improved reporting on "Outbreaks"/ Clusters of COVID-19 (Indicator 7, in Table 4)}

"Outbreaks" are clusters of cases that reflect a social or physical context where COVID-19 is higherthan-average and where, given the exponential spread of COVID-19, there needs to be concern for further spread. The public health system is charged with the responsibility for investigating and reporting "outbreaks" of infectious disease, including COVID-19. It is reasonable to expect that this mission includes informing the public about that particular aspect of patterns of pandemic spread. Without such empirical information and diligent analysis, the usual public recourse is to "magical thinking". Unfortunately, county public health departments in the San Joaquin Valley region have moved slowly and unsteadily in investigating outbreaks. ${ }^{10}$

CDC provides rudimentary guidance to county public health departments that include examples of settings which might be identified as the locus for an outbreak: congregate settings, correctional facilities, workplaces, hospitals and other healthcare settings, schools and child care settings, homeless shelters. However, an omission that is surprising in light of various analyses of "super-spreader" events, the CDC guidance provides no encouragement for categorization and reporting of event-related outbreaks as nodes within a range of social networks: funerals, weddings, holiday celebrations, religious gatherings, public ceremonies such as the Rose Garden announcement of a Supreme Court nominee [52,53].

CDC's stance that "outbreaks" must be defined within a local context, is another significant factor giving rise to the inconsistency in county public health departments' visualization of outbreaks, and the extent to which they share analyses of information collected with the public. In the case of farmworkers and COVID-19, it appears that the generality of CDC guidance on requirements for timely investigation of outbreaks, coupled with lack of clarity in defining agricultural employers' responsibilities for case investigation and contact-tracing, also undermine the priority given

\footnotetext{
${ }^{10}$ I do not have access to internal data on public health department investigations of COVID-19 but the size of several major outbreaks where cases continued to climb over a period of several weeks suggests that counties moved too slowly or ineffectively with contacttracing. At the same time, there is also evidence that some investigations are being conducted and helping to mitigate outbreaks but without public reporting, public health system performance in this critical area cannot be definitively assessed.
}

by county public health departments to investigating and reporting to the public on outbreaks ${ }^{11}$

Ultimately, CDC's lack of clear mandates on COVID19 outbreak investigation gives license to county health authorities to develop subjective definitions of what constitutes an outbreak. Consequently, counties' reporting on outbreaks reflect the laissez faire context CDC has fostered. Each has developed idiosyncratic, approaches to identifying and reporting what they consider to be outbreaks. Poorly-reasoned assertions that identification of outbreaks would violate privacy provide no evidence that an actual "privacy impact assessment" was conducted to assess the implications of reporting procedure. Public statements by the county health departments instead suggest there is often intense political pressure from businesses where there are outbreaks to avoid publicity rather than share information on the relative riskiness of different sorts of work environment.

\subsubsection{Overcoming business-driven pressures to report outbreaks}

Merced County is one of only two counties in the region that currently report outbreaks on their COVID-19 dashboards. Merced County's proactive stance probably relates to the fact that there was an outbreak at a large poultry firm, Foster Farms, where 392 cases were identified before the county public health officer was able to place an order in effect to force a temporary closing [54,55]. However, although Merced County is now leading the way by listing outbreaks, it only names places (e.g. "Liberty Packing", "Los Banos Sheriff's Office"), without explicitly documenting the types of establishments where outbreaks occur, the size of outbreaks (either as indicated by \% of workers who test COVID-19+, incidence of new cases, or total numbers cumulatively infected). It has taken one good step forward. More will be needed.

In general, the regional reporting of outbreaks is so minimal that it deprives the public, most crucially, workers at affected worksites or other venues, of the information necessary to make informed decisions to min-

\footnotetext{
${ }^{11} \mathrm{CDC}$ 's guidance to agricultural employers, for example, requires employers to report to the local public health department when they find out that they have 3 or more confirmed COVID-19 cases. They are also advised to consider ways to inform the close contacts of COVID-19+ workers but are not provided guidance on methods of contact-tracing. Their further responsibilities vis-à-vis outbreak response is stated as being to follow public health department instructions. See https://www.cdc.gov/coronavirus/2019ncov/community/guidance-agricultural-workers.html.
} 
imize their own personal risk of contracting COVID-19 or to advise family members about risk reduction. ${ }^{12}$

\subsubsection{Explaining why improved reporting of outbreaks is crucial}

It will be important for local public health advocates to better communicate why improved reporting on COVID-19 outbreaks yields both economic and public health benefits in order to overcome business opposition to what they see as public relations threats. Public health officials will need to help by explaining exactly why an incipient outbreak cannot be effectively "managed" through information suppression - because the consequences of an uncontrolled outbreak are likely to be worse than temporary bad publicity in many cases.

The consequences of a public health department not providing detailed statistical reporting on a workplace outbreak of COVID-19 are serious. Minimal reporting from the public health department on a workplace outbreak of COVID-19 at a pistachio-processing plant in Wasco, Kern County, contributed to the eventual size of an outbreak that ultimately affected 150 workers and numerous family members in workers' households [56]. In the absence of definitive official reporting on the outbreak from the county public health department a national news story in Forbes reported three weeks after the outbreak was first detected that workers were saying "everybody" was infected [57,58]. Well-designed objective reporting, and public dissemination would surely have contributed to distinguishing "some cases" vs. "lots of cases" vs. "everyone".

However, there is a good example of an instance in which an outbreak of COVID-19 among H-2A guestworkers in congregate living generated a proactive business and public health system response. After a large July outbreak of COVID-19 in a congregate living facility for $\mathrm{H}-2 \mathrm{~A}$ workers in Ventura County in which 204 of the 216 workers in the facility were found to be COVID-19-positive the county, and Santa Barbara County adjacent to it, issued health orders requiring daily screening for workers in congregate housing [59]. However, the outbreak was only detected as a result of

\footnotetext{
${ }^{12}$ There are additional inconsistencies that make it harder to assess "how it's going" in one county or another. Kings County, for example decided not to include cases at Avenal State Prison in its tallies of county cases although the prison cases make up about $45 \%$ of all the cases in the county. The decision to separate the facility domain from the "community" domain is bureaucratically understandable but not justifiable because the prison "hot spot" infects employees at the facility who, in turn, infect family members and others.
}

responsible and proactive efforts by the facility manager.

Proactive response rather than information suppression yielded public health benefits by decreasing local community spread and international COVID-19 spread as workers returned home to Mexico as well as mitigating spread in the local farm labor force, a development that would have had negative business consequences for producers. However, dissemination of details on the outbreak investigation (e.g. if determined, the extent to which transmission occurred in cooking/eating spaces or in sleeping quarters) would have widespread utility in informing employer practices.

\subsection{Indicators for monitoring public health system operational success}

Local statistical reporting needs to include, in addition to the Indicators about the spread of COVID19 itself, additional indicators to monitor county public health departments'progress in meeting the urgent objectives of pandemic control. Enabling such transparency and accountability, empowers the public to understand how their funds are being spent, the impact that spending is having and providing all partners in the fight against the pandemic insights to offer wellreasoned input suggestions for improvement. Table 4 includes two sets of indicators not currently in place that I suggest need to be added:

- Indicators 8-9 are indicators of the speed of public health system response

- Indicators 10-13 provide metrics to assess important dimensions of quality of response.

These are discussed below.

\subsubsection{Metrics for monitoring the speed of public health system response}

Public health system effectiveness in decreasing the time interval from infection to isolation is a key element in COVID-19 response and careful monitoring is needed to assess and refine efforts to do this and contact-tracing is a crucial tool for accomplishing this. Relevant data on local public health department performance in contact-tracing need to be systematically collected, analyzed, tabulated, and reported to fulfill the promise of organizational self-monitoring as a tool for leveraging improvements in system performance.

Below I discuss the two monitoring indicators related to speed of local public health system response to COVID-19 that can provide insights that can contribute significantly to system performance 


\section{Indicator 8 - Time from Seeking Testing to Securing Testing}

Every delay from the point an individual is infected to the point when they secure COVID-19 testing contributes to spread of the pandemic. Analysis of Indicator 8 data should ideally include information on populations or geographic areas considered to be at higher risk of encountering difficulties in securing testing. ${ }^{13}$ Public reporting on lags from seeking to securing testing can not only provide incentives to county public health departments to decrease waiting time but, also, nurture reluctant individuals' willingness to decide to seek testing or forego it.

Why time from seeking testing to securing testing, a standard indicator in myriad customer-oriented service delivery systems, is not currently measured is unclear. Although data collection burden is surely a concern, the lack of reporting on wait time can lead to or reinforce "testing deserts". Data related to "customer wait time" and even customer satisfaction with enhanced testing support could be gathered fairly easily by queries to individuals at the point they successfully secure testing: When did you first try to get tested? How did it go today? How could we do better?

Such information might also be generated automatically in some cases (by logging online registration or phone call-in for an appointment and linking that to appointment date) and sending followup text-based surveys of satisfaction. Retailers routinely implement such self-monitoring efforts via surveys of random samples of their customers. Random sampling that reliably represented the individuals being tested would be adequate to generate good information for Indicator 8 without incurring the cost of $100 \%$ reporting.

Indicator 9 - Time from Testing To Securing Test Result and Successful Isolation/Quarantine

Time from testing to securing testing result - can be systematically and reliably measured and is beginning to be reported in some jurisdictions. Happily, one of the eight counties in the region (Stanislaus) does publicly report this crucial indicator of average time from testing to securing results. However, none of the other counties in the region currently have metrics in place to measure, analyze, or report the delay stemming from the point an individual secures their testing results to the point at which they can secure quarantine or isolation.

\footnotetext{
${ }^{13}$ There have been reports of indigenous farmworker families, many of whom lack Internet access, who have had trouble getting through phone operators to register for testing. In other cases, farmworkers have had to drive more than 1 hour to access free testing.
}

The reason Indicator 9 is so important is that the public health system has unaccountably acted on the tacit assumption that "advice" from a public health department caller or the threat of a "public health order" would assure compliance and reduce transmission. It doesn't necessarily do this. Notification is not enough; encouragement and assistance is crucial to actually impact farmworker self-isolation and self-quarantine.

Moreover, the entire CDC strategy of controlling transmission by recommending that COVID-19+ individuals simply "go home and isolate themselves" totally ignored the reality so prevalent in many low-income, and especially in low-income farmworker communities that, in crowded housing, home isolation is infeasible. Fortunately, the need for alternative housing and case management assistance to secure it are now receiving attention, at least in California. ${ }^{14}$

Having systematic reporting on the extent of local public health system success in convincing people to isolate, and the time it takes to implement the isolation for those living in crowded households, could be very helpful in working effectively to contain the spread of the virus.

\subsubsection{Metrics for monitoring public health system quality: Success in carrying out necessary contact-tracing activities to control COVID-19 spread}

Focus on speed and efficiency have compromised contact-tracing. Looking at the bottom line in relation to yield of successful contacts and adequacy of information secured is crucial - especially since failure rates are known to be high. In this section I specifically recommend 4 indicators (Indicators 10-13) related to the implemented efficacy of this intervention - i.e. the quality of contact-tracing.

Indicator 10 - \% identified cases interviewed for contact elicitation $w /$ in 48 hours from test

This indicator tracks quality of case investigation by measuring success in reaching and conversing with infected individuals in a way that manages to

\footnotetext{
${ }^{14}$ Early on in the pandemic, there were proactive efforts which involved collaboration between agricultural employers and local counties and/or non-profits to secure alternative housing accommodations for COVID-19-positive individuals who could not effectively selfisolate in their current surrounding. However, reports from the field are that many farmworkers do not know of the support available to them if they test positive and don't understand or are worried about what they are getting into should they opt in. Information about available support for isolation for those who need it is sometimes but not routinely available either in general or at testing sites.
} 
elicit the full range of contacts who could have been infected with COVID-19 - with the benchmark of 48 hours based on the importance of speed in the case investigation/contact-tracing process. Speed in reaching cases is crucial for both "backward" contact-tracing (case investigation) and standard "forward" contacttracing.

Indicator $\mathbf{1 0}$ is valuable because more rapid connection and more robust communication with cases directly reduces further spread of infection by getting their close contacts tested as rapidly as possible and quarantined if need be. Reports about contact tracing "yield", i.e. successful thorough interviews, indicate concern about speed and success in reaching contacts is warranted, because as few as $35 \%$ of those contacted may be willing to give contacts - especially if the contact tracer does not personally "connect".

Contact tracing is an important intermediate step in COVID-19 data collection methodologically akin to snowball sampling (known to be very useful in sampling "hard to reach" populations). Efficacy of contacttracing contributes directly to representativeness of testing data. However, it needs to be remembered that from a data collection perspective, in addition to reaching all identified "close contacts" elicitation of information about their close contacts needs to be fairly complete.

Indicator 10, therefore, among other facets of public health system contact-tracing operations (e.g. database quality and user interface, scheduling of contacts, mode of contact), can provide an actionable indication of the cultural and language competence and communication skills of contact-tracing staff, their knowledge of the community, and different contexts where social mixing is likely to take place, as well as standard call training and implementation issues. Ideally, system performance might be measured for success in reaching the hardestto-reach groups.

Indicator 11 - \% of contacts identified by cases interviewed within 48 hours

Success of contact tracing rests both on reaching and talking with contacts rapidly and reaching all of them. Difficulty of reaching close contacts identified by COVID-19+ individuals inevitably varies, so it is unreasonable to expect $100 \%$ success since even well-funded, diligent systems have reported contact success as low as $60 \%$. Nonetheless, even if fair benchmarks are hard to establish, simply tracking trends in reaching contacts can provide useful insights into what's working, what is not, and where improvements are needed.

It's worthwhile noting that most of the contact tracing to date has been initialized based on results from PCR- based tests, which where, at best, 1-2 days is required to obtain results and where, at worst test-turnaround time exceeded 7 days - a lag that is generally believed to make testing useless in mitigating COVID-19 spread. With rapid-turnaround antigen testing it becomes possible to determine COVID-19 positivity virtually instantly, thereby making an immediate contribution to controlling spread.

Indicator 12 - \% of new cases linked to other cases This indicator, based on recommendations from $R e$ solve To Save Lives, is essentially a contact-tracing "completion rate". If a local public health system is consistently unable to link new cases to previouslydetected cases it is failing in its case investigation efforts. This may be because it is not getting adequate information about the context of exposure, because the contact may not be willing to divulge all of their contacts, because of communication skill issues; or other difficulties, e.g. in reliably determining "close contacts" within a large numer of contacts overall. Reasonable benchmarks for assessing system performance are not yet clear - since case investigation cannot be expected to provide definitive evidence of the source of exposure in all cases. However, in many cases it can, and success in COVID-19 control is directly related to these linkages and, even if expectation cannot be benchmarked, trends are relevant.

Indicator 13 - \% of new cases among quarantined contacts, by week

This indicator, also based on recommendations from Resolve To Save Lives, is framed so that the desired goal is $100 \%$. It indicates that the local public health system's efforts to speedily quarantine infected individuals is working - successfully assisting the contacts of COVID-19+ cases to quarantine themselves.

Again, issues of language, cultural competence, communication and appropriate mobilization of needed resources for food and economic insecure individuals are part of the challenges here. Indication of a low \% may be a function of staffing, training, and/or a measure of successful engagement with and knowledge of the community in which they are working. In some instances, in-home isolation may work well, but in some others, not so well - but here the indicator can be designed to reflect the "client mix" in order to assure that crowded farmworker households are being equitably served.

\subsection{Improving COVID-19 data collection: Better data, better outcomes}

Better tabulations of the epidemiological data on COVID-19 currently being collected by county health 
departments are feasible and affordable with modest investments of effort.

Improving the quality of data collected from testing is more challenging but a necessary investment in improving the reliability of reporting based on those data.

The San Joaquin Valley counties have sought, with limited resources, to facilitate farmworker access to COVID-19 testing. Their success has varied. Some have been proactive and innovative while others have not. However, unfortunately, it has not been adequately understood that efforts to secure more representative data on incidence of COVID-19 simply by increasing volume of testing do not necessarily lead to representative data.

Sample bias in testing for COVID-19 constrains the reliability of statistical data derived from that testing. From a statistical perspective, the broad push to increase reliability of reporting on the COVID-19 pandemic by promoting a higher volume of testing is very helpful but does not necessarily solve the underlying problem of sample bias. The regulatory indicator, referred to by the state as "volume" of testing (which I refer to as "density" of testing) inevitably increases the possibility that more widespread COVID-19 testing will generate more representative sampling but does not guarantee it.

A cause of testing bias - a universal challenge that is, however, more pronounced in the farmworker community than in some other populations - is that the sample of individuals who do seek testing very seldom includes asymptomatic individuals and underrepresents those with very mild cases. This is because lack of economic support for isolation or quarantine provides a disincentive to economically-strapped farmworkers to seek testing due to apprehension that testing might show they are COVID-19-positive. It will be necessary to make testing seem overall "easy and desirable".

The representativeness and overall quality of COVID19 test-derived data can be greatly improved by giving attention to ways to make the diagnostic encounter effectively contribute to isolation or quarantine and improve vulnerable populations' access to health advice and support services. An approach to testing based on providing "enhanced testing encounters" can improve the representativeness, richness, and reliability of data collected by fostering willingness to seek testing.

Below, I identify some useful features of current COVID-19 data collection by the San Joaquin Valley counties that stem from the need to serve a socioculturally diverse population and suggest improvements that will enhance these endeavors.

\subsubsection{Positive developments in local COVID-19 testing and suggested improvements}

Each of the options discussed represents a way to improve representativeness of the sampling frame (individuals tested) as a basis for reporting the actual number of COVID-19 cases.

\subsubsection{Partnerships with community health clinics to make COVID-19 testing in the farmworker population more representative}

Community health centers are established widelytrusted resources for farmworker families due to availability of sliding-scale fees for service and linguistically/culturally capable staffing. Consequently countyclinic partnerships are very useful in reducing language and access barriers that keep some sub-populations, including farmworkers, from being tested. Fortunately, some of the San Joaquin Valley counties partnered with these community health centers (FQHCs - FederallyQualified Health Centers) early on in the pandemic (April-May) to offer free COVID-19 testing at many locations throughout their service areas as a way to make testing more accessible.

However, the system was slower in expanding to the outlying farmworker communities than in setting up testing sites in more urban areas but broadening these partnerships is a positive step in improving representativeness of testing data. As a next step, counties will need to undertake targeted "marketing" efforts to attract sub-populations within the farmworker population who are less motivated to seek testing (e.g. indigenous language minorities not yet reached effectively by community outreach workers, more recently-arrived young male migrants).

It will be particularly important to make sure that the testing encounter is used as an opportunity to develop lasting relationships with the $30 \%-40 \%$ of farmworkers who do not currently have a "medical home". This is a customer service initiative that will pay off by increasing sample representativeness due to wordof-mouth communication by satisfied customers about how COVID-19 testing is friendly and how testing was important to their and their families' well-being. Even if the results of their initial testing encounter show them to be COVID-19-negative, new clients of the community health centers who have gotten useful advice and support will probably be more willing to seek testing in the future if/when they are worried about close contacts with a COVID-19-positive individual. 


\subsubsection{A belated but welcome step forward: California state mandate for adequate COVID-19 testing per $100 \mathrm{~K}$ population coupled with a health equity metric}

California has begun to rely more heavily on statistical reporting as a management tool in efforts to move counties forward to more aggressively and strategically combat COVID-19. In September, state government pushed county public health systems to increase their COVID-19 testing rate by conditioning approval of county plans for "opening up" their economy by relaxing state-mandated social distancing regulations for local businesses (using a color-coded "traffic light" style system of tiers representing decreasing incidence of COVID-19). Progression to less restrictive tiers is linked to evidence the counties are conducting adequate testing based on a formula that incorporates two separate factors: adequate \# of tests/100K population, positivity rate among tests. [60]. ${ }^{15}$

Inclusion of the "health equity metric" in California's regulations for reporting on COVID-19

California's metrics for approving counties' reopening also now require tracking the COVID-19 positivity rate in disadvantaged neighborhoods (the lowest quartile of census tracts as measured by the Healthy Places Index - an indicator based on community characteristics available from ACS or other standard data sources). The expectation that sub-areas in each county should achieve similar levels of success in pandemic control.

The state requires counties to prepare strategic plans with specific activities to overcome COVID-19-related disparities in disadvantaged neighborhoods and communities [60]. California's decision to include this additional indicator of health equity as part of its framework for incentivizing local COVID-19 control efforts is a welcome and well-designed one. It is the first such effort in the U.S. and will, hopefully, bolster local county government resolve to generate the statistical information needed and to take the steps necessary to meet the state's expectations.

However, the new initiative has been controversial among some local-level public health officers who complain the state is expecting too much from them. It is to be expected that the Healthy Places Index used to identify the problematic neighborhoods may need to be tweaked because the data on COVID-19 weekly in-

\footnotetext{
${ }^{15}$ Understandably, given the legal and political context, county testing adequacy is assessed excluding cases in prisons (since testing decisions are made by the state for them). There are also special provisions for very small counties.
}

cidence is, inevitably, "noisy" but the basic utility of the health equity measure is clear-cut. California's approach provides a straightforward and direct way to overcome the glaring variation in impact of COVID-19 on disadvantaged communities such as the farmworker ones that are the focus of this analysis.

It deserves note, given the counties' complaints, that the newly-imposed state metrics for tracking patterns of COVID-19 do not require new data collection, only new tabulations and reporting. Presumably, the "burden" that is being objected to is not related to agency workload but to local political environment. The "burden" being complained about seems to be primarily the state's expectation that counties actually bring down COVID-19 transmission.

\subsubsection{Testing "whole-households" at once using rapid-turnaround antigen testing}

The Rockefeller Foundation [61] and experts [62] have argued that antigen testing has great promise for COVID-19 screening in workplaces and schools - because it provides rapid turnaround of test results (within 15 minutes) and because the cost/test is much lower than for PCR/molecular testing. Utilization of this specific technological solution to identifying cases requires careful attention to issues of measurement error and testing logistics (primarily false negative results) but provides a powerful tool to use to improve the representativeness of the sample of tested individuals that provides the basis for reporting, analyzing, and tracking COVID-19. Using rapid-turnaround testing to test the entire household of each individual who seeks testing because of feeling ill or worries about close contact with a COVID-19-positive person cost-effectively improves representativeness of the sample of tested individuals.

From the perspective of quality of data collected and sound reporting of COVID-19 in a farmworker community, the whole-household testing model has the great advantage of providing an excellent opportunity for detection of asymptomatic cases, the apparently healthy population least likely to seek or secure testing. Including these "silent" sources of COVID-19 spread is a prime objective both in terms of immediate action to mitigate spread and as a longer-term investment in reliable surveillance data since improved detection of asymptomatic cases moves us toward a more accurate measurement of COVID-19 prevalence.

Whole-household testing also jumpstarts case investigation by rapidly setting the stage for eliciting a full inventory of the close contacts of infected individuals - discussing simultaneously close contacts who pos- 
sible sources of the index case's infection retrospectively (case investigation) and those who the index case might have infected (contact tracing). Using community health workers who are likely familiar with (and who likely have worked themselves or had family members work in agriculture) makes it easier to identify venues and opportunities for infection, so the questions asked to elicit contacts can be more targeted. For example Who did you stand next to when the Friday checks were being handed out by the crewleader? And for how long? How crowded was the van you rode in going to work? Was everyone wearing masks or not?

Recall is always an issue in contact tracing. By eliminating the temporal gap between testing/diagnosis and initiating contact-tracing, it is likely that quality of an index case's recall can be improved (since the reference period is typically about 1 week prior to presumed data of infection). By eliminating the social distance between the data collector (in-person conversation with a contact-tracer embedded in the whole-household testing team) and the COVID-19-positive index case it is possible to elicit a more complete inventory of close contacts is inevitably better than the inventory elicited in even the best "cold call" by a telephone interviewer from a "government" (public health) agency.

Improvement in case investigation and contacttracing success as well as quality of information elicited in a face-to-face encounter, then, can significantly improve the representativeness of community-level sampling because, of course, the contact-tracing process is, from a research/surveillance perspective, a method to generate a snowball sample. Methodological analysis of survey research in hard-to-survey populations suggests that snowball sampling competes very well with standard multi-stage random sampling using standard lists - but only if there is trust between the interviewer and the respondent.

ÓRALE COVID-19-upcoming: A pilot of the recommended improvements - tailored to farmworker communities

A new initiative by the University of CaliforniaDavis, ÓRALE COVID-19, initiated as part of the National Institute of Health's RADX-UP (Rapid Acceleration of Diagnostics-Underserved Populations) will take advantage of the low cost of antigen testing by transforming testing deployment based on rationing of test access to an approach that promotes "whole household testing". The approach will be to provide free mobile testing that is accessible by farmworker families close to home and encourage not only individuals who may be worried about whether they have contracted COVID-
19 but, also, everyone in their household to come to the local test. ${ }^{16}$ It is expected that this approach can address four issues that currently constrain the reliability of testing data. Whole-household testing can be expected to:

1) increase identification of asymptomatic cases of COVID-19 (family members who are close contacts of a person seeking testing because of exposure or illness

2) By reducing fear, uncertainty and stress, encourage household members to rapidly seek help if/when further testing is needed down the road due to a new exposure

3) By effectively arranging wrap-around services for farmworkers who are ill with COVID-19 improve "customer" satisfaction and encourage them to encourage others to seek out testing

4) By managing the possible requirements for retesting of false negatives, given limitations of antigen testing, improve detection of COVID-19 cases (since a primary reason for a false negative test is testing too soon after infection before viral load has built up).

\subsubsection{Deploying rapid-turnaround testing in community-friendly high-traffic venues}

Survey research with various hard-to-reach populations (e.g. men having sex with men, undocumented immigrants, Latino immigrant households the San Joaquin Valley) has shown that enhanced intercept interviewing (time-space continuum sampling) can yield a more representative sample of the farmworker and immigrant population than standard multi-stage sampling (because the initial sampling frame available in standard address lists) is typically systematically flawed due to omission of the most marginalized households - in particular those living in hidden, illegal housing units adjacent to a "main house".

\footnotetext{
${ }^{16} \mathrm{~A}$ family of five might arrive at the mobile testing van at a local park or school, a 5-minute walk from their house. While waiting for test results, community health workers on the testing team can establish an informal relationship with the family, secure initial information from each on their close contacts outside the household, and initiate discussion of ways in which a family member could selfisolate if it turns out someone in the household is COVID-19-positive. If it turns out the COVID-19-positive individual in the household is a breadwinner, discussion could, turn immediately to options for securing economic support during self-isolation. Or if the COVID-19 positive person is a child, conversation could move toward talking over precautions to minimize within-household transmission, and other contacts who may be at risk, such as parents'work mates, other students, family, etc.
} 
A similar rationale makes rapid-turnaround testing in community-friendly high-traffic venues helpful as a way to decrease sample bias in COVID-19 testing. An advantage of systematically identifying promising testing venues (surveillance points) after developing a full inventory of frequently-visited venues in a community (e.g. ethnic grocery stores or supermarkets, play areas, flea markets) is that sampling/testing venues can be chosen to recruit a particular sub-population to test that might not otherwise be easily reached (in the San Joaquin Valley, for example, Punjabi farmworkers, a growing portion of the labor force).

Another potentially promising approach might include testing provided at special community events or celebrations; such events have already been used for many years to offer health screening to hard-to-reach populations.

The viability of these approaches has been demonstrated in a low-income Latino neighborhood (the Mission District of San Francisco) by a research team from the University of California, San Francisco (UCSF), a leading institution in research on and response to COVID-19. UCSF initially offered PCR testing in community-friendly venues such as schools and parks by partnering with a community-based coalition, Unidos en Salud, to advertise and promote easy-access testing. They subsequently offered testing at a heavilyused BART plaza (Bay Area subway system station) that is the center of the neighborhood.

The UCSF research team's description of the demographic and socioeconomic profile of the population tested in April provides a good idea of the utility of the approach. Although the testing data over-represented affluent White households in the target census tract, the Latino sub-sample appears to be representative of the local heavily immigrant, "hard to reach" population. Additional data collected during the in-person testing encounters show that sample bias, while observable, can be adjusted for when the testing encounter includes queries to securekey demographic and socioeconomic descriptors of the individual being tested (as distinct from standard testing encounter where only a bare minimum of demographic information is collected).

\subsubsection{Promoting bi-weekly antigen test screening at agricultural worksites}

Agricultural employers typically use temperature and symptom observation as screening tools for workers coming to the site. Even though this practice is based on CDC guidance, these are, unreliable measures for identifying COVID-19-positive individuals because they miss the pre- and a-symptomatic individuals. Only about $40 \%$ of COVID-19+ individuals initially present with fever and a high proportion of transmission $(50 \%)$ is from pre-symptomatic individuals. About $40 \%$ of all cases are asymptomatic [63].

Instituting bi-weekly workforce screening using antigen testing can improve the representativeness of the sample of tested individuals because it is not based on personal preference/demand for testing but is close to a $100 \%$ sample of the farmworkers at each site tested. It can be expected to identify a-symptomatic and pre-symptomatic individuals as well as those who are feeling mildly ill. If repeated bi-weekly, say, on Mondays and Fridays, it will be possible to identify pre-symptomatic individuals who tested with a falsenegative because their viral load had not built up enough since infection. Bi-weekly testing presents an attractive balance between accuracy and cost because the mean time from infection to symptoms in COVID-19 is about 5.5 days and viral load rapidly builds up from 2-3 days after infection and persists for an additional 5-7 days.

It is not clear to what extent agricultural employers will be willing to implement routine workplace screening, however, because there are costs and logistics entailed - potentially both for workers'time, testing personnel, and testing kits. ${ }^{17}$ However, such costs can be framed as "COVID-19 insurance". Part of promoting rapid-turnaround testing to replace fallible temperature screening and identify "seeds" of outbreaks at a worksite will require messaging to agricultural employers about the cumulative costs of an undetected COVID-19 outbreak at their worksite.

Ultimately, adoption may rest on the specific testing solutions available in 2021 [64,65]. The ideal test would be an antigen test requiring only a saliva sample (more user-friendly than nasopharyngeal swabbing and according to some reports more reliable). However, it is not yet clear exactly when such tests will become available.

\subsubsection{Improving messaging to encourage more widespread efforts to seek COVID-19 testing}

Incomplete information and misleading beliefs fostered by flawed CDC messaging about COVID-19 that were subsequently copied by the downstream public health entities disseminating information to the public

\footnotetext{
${ }^{17}$ Total costs for workplace screening of farmworkers using antigen testing should be about $\$ 160 /$ worker/month - including the cost of tests, testing personnel, and paid time for workers being tested. Such costs can be seen as "COVID-19 insurance".
} 
have had a negative impact on the motivation and aspirations of farmworkers (and others) uncertain about whether or not to seek testing for potential COVID-19.

CDC's efforts to downplay both the risk factors contributing to likelihood of SARS-CoV-2 infection and consequences of COVID-19 illness, have, simultaneously undermined response and compromised the reliability of epidemiological reporting on COVID-19 spread by decreasing efforts to seek testing, thereby contributing to sample bias.

Improved messaging on COVID-19 transmission e.g. via aerosol and from minimally symptomatic or asymptomatic children to adults and vice versa - as well as full disclosure of possible health consequences of COVID-19 (e.g. prevalence of "long-haulers" unable to work for 2-3 months or longer, cardiovascular sequelae even among asymptomatic cases) can have a positive impact by strengthening the resolve of asymptomatic and minimally-symptomatic working-age farmworkers and their family members to seek testing or diagnosis by a health care provider.

To date, the county public health systems in the San Joaquin Valley have relied primarily on mainstream media for informing the public about COVID-19 and did not, until August, 2020 begin to implement much messaging to reach vulnerable populations such as farmworkers to provide anything beyond broadly-framed basics - presumably due to the hierarchical nature of the U.S. public health system making them feel that going beyond CDC pronouncements is risky.

Public pressure for accountability will be required to nudge them toward taking the necessary step toward "full disclosure" of the facts about COVID-19 but, once they do, it is reasonable to expect the benefits will include improved uptake of testing opportunities and improvements in representativeness of testing data that are collected.

\section{Conclusions - The role of local statistical reporting and how it can and should help to stamp out COVID-19}

The traditional view that epidemiological data, statistical analysis, and findings should simply be produced, framed, and disseminated to communicate with a relatively homogenous audience of professionals is untenable in the context of COVID-19 response. In an era with worrisome anti-science stances taken by national leaders in a number of countries and where critical policy and programmatic decisions are made on the basis of complex statistical tabulations that are increasingly contentious, the need for transparency and clarity in official agencies' reporting of statistical information to the public is increasingly urgent. Improved statistical reporting at the local level is crucial because local data collection and reporting are the foundation for state and national reporting and formulation of strategic response.

The immediate challenge is to better configure communication on patterns of COVID-19 transmission and consequences of COVID-19 illness to the public - because this is the most powerful and, for the moment, only tool available in the battle.

However, there are also long-run reasons for improvement. To sustain sound, functional democracy in the $21^{\text {st }}$ century where so many decisions are based on analysis of a torrent of statistical data, it is necessary to find effective ways to generate and disseminate information to "the public". This requires thoughtful presentation of relevant and reliable information to diverse audiences within the general public (such as language minorities, and in regions such as the San Joaquin Valley, the farmworker households and local civic activists) to enhance their ability to make significant, positive contribution to the collective efforts to suppress the pandemic - even as vaccine(s) and better treatments become available.

There are now opportunities to reboot U.S. national response to the COVID-19 pandemic. But the unsteady trajectory of United States official statistical agencies, CDC, HHS, FDA, and various other federal agencies (e.g. the Department of Labor's Occupational Safety and Health Administration) in disseminating crucial statistical information on COVID-19 during the first year of the pandemic has jeopardized not only public participation in dialogue and decision-making about COVID-19 response but exacerbated inherent conflicts between economic and public health priorities.

Dysfunctional national leadership has also contributed to a cascade in which failures and distortions at the top of a hierarchical public health system were propagated downward to states, and to local government, i.e. counties, and municipalities. It is now time to transition into more effective national-state-local collaboration in confronting the pandemic.

The inconsistently and vaguely-articulated definition of "outbreaks" and "type of transmission" are cases in point. Statistical analysis and reporting need to be better linked toward hypothesis generation - toward suggesting strategic priorities and "pressure points" for more effective intervention. It is possible that county public health authorities want to leave hypothesis gen- 
eration and testing to academic researchers, but in actuality, more public engagement and input, collective inquiry and a form of "crowdsourcing" for identifying action-research directions, has great promise.

Improvements in the local "feeder" system for generating and disseminating statistical information can allow stakeholders to more clearly discern the dimensions of the pandemic and respond better. Improved reliability, clarity, and precision of information from county public health departments are needed as a basis for generating deeper insights into the epidemiology of COVID-19 and in order to generate the best possible input for strategic local government response (i.e. level of funding, priority-setting, programmatic initiatives) to suppress transmission.

Although the current analysis focuses on a specific vulnerable population in a distinctive sociopolitical context (communities in California with high concentrations of immigrant farmworkers), similar issues are likely to arise in local, national, and international COVID-19 response across the globe - especially in regions and countries with a good deal of ethnic/racial diversity and/or socioeconomic disparities. Because the San Joaquin Valley has so many similarities to the situation in less-developed countries - underfunded public health agencies with limited management and professional capacity being confronted with a major crisis - lessons learned from the U.S. experience are quite relevant to global pandemic strategy.

This can be seen from the situation in Mexico a middle-income country - where authoritarian antiscience national leadership coupled with serious missteps in plans for generating sound statistical data on the impact on COVID-19, has resulted in a tragicallyflawed response to the pandemic. Mexico's arrogant reliance on its Instituto Mexicano de Seguro Social (IMSS) Clinics to provide an adequate sentinel system for monitoring COVID-19 response, despite wellknown shortcomings, shows the tragic consequences of statistical reporting where the official statistical data collection and reporting strategy is designed to demonstrate a convenient, preferred outcome - i.e. the minimal impact of COVID-19 [66]. Unfortunately, similar processes have threatened the integrity of the United States' reporting on COVID-19 as President Donald Trump called for "slowing testing down" $[67,68]$ and antipathy toward assessments by researchers, epidemiologists and public health officials, undercut efforts to reduce transmission through use of face masks and requirements for social distancing in business, and jeopardized public trust in potential vaccines.
The analysis presented here shows that even with limited public health system resources it is not too difficult to go beyond a rudimentary framework of reporting on COVID-19 in local jurisdictions to provide a quantitative estimate of the extent of the disproportionate impact of COVID-19 among farmworkers and their families. The analysis presented here offers straightforward practical steps that can be taken to identify the specific societal factors contributing to the disproportionate impact of COVID-19 on the vulnerable population of farmworkers and their families.

The analysis of cumulative incidence of COVID19 in farmworker communities also shows that the "impact" of COVID-19 on the vulnerable population of farmworkers, is not fully captured by analyzing race/ethnic disparities. The analysis identifies several specific socioeconomic factors that need to be well understood and urgently addressed to assure optimal response: work in an essential industry, overcrowded housing, lack of access to testing due to maldistribution of testing sites, and hesitation within the population to secure testing and/or health care due to the lack of economic support and wraparound services to make self-isolation or quarantine viable for undocumented workers ineligible for pandemic assistance.

This sort of analysis of the situation in the San Joaquin Valley and other areas of labor-intensive agricultural counties in California and across the U.S. shows that reporting on COVID-19 as it affects a particular vulnerable population such as farmworkers does not entail untoward burden. It is technically feasible without undue expenditure - based on identifying farmworker communities and looking at the impact COVID-19 has had on each.

California took a bold and innovative step forward in October by instituting its new "health equity" metric as a factor in state approval of counties' "opening up" for less-intensive social distancing in businesses. This will hopefully nudge recalcitrant local government toward serious, proactive efforts to generate better data and to analyze those data and deploy insights based on those analyses to improve response. They will need technical assistance in doing this. However, even with serious state and local budget pressures from the pandemic, there remains unallocated federal funding for emergency response to COVID-19 and, hopefully, a new federal administration that places a greater emphasis on public safety will pitch in to assist also.

It is unfortunate that 2020 has been a year in which the ongoing conflict between scientifically-driven decision-making popular demand for relaxation of the 
"non-pharmaceutical" intervention measures that were necessary to manage the COVID-19 pandemic has been so intense. This ideological conflict has been incorrectly framed by anti-science politicians as one that pits "technocracy" against "democracy". But, the debate can be more usefully re-framed as dialogue as to how one strand of evidence-based decision-making, in this specific case, statistical reporting, can be improved so as to better contribute to the collective and widelyembraced objective of meaningfully engaging the full spectrum of community members, in this case, not just the elite, but also Latino/a farmworkers, their families, and the civic activists and local leaders in their communities, in empirically-based, rational discussion of the best practical strategies to confront COVID-19.

To accomplish this, it will be important to keep in mind that the hoped-for panacea of a COVID-19 vaccine will not provide an immediate solution to the COVID-19 pandemic, that civic engagement will still need to play a crucial role in COVID-19 response. Dr. Anthony Fauci, Director of the National Institute for Allergy and Infectious Diseases, a national leader in COVID-19 strategy, explained in mid-September that most of 2021 will be a year in which response strategy will require both non-pharmaceutical interventions and diligent efforts to distribute whatever vaccine becomes available and promote uptake [69].

Hopefully, farmworkers will rank high, along with other high-risk populations such as health care providers, public safety personnel, and other vulnerable populations such as the homeless and elderly residents in long-term care facilities, in national and state priorities for COVID-19 vaccination. Strategically, it will be desirable to have farmworker-oriented vaccination campaigns underway before the peak summer season of 2021 draws farmworkers back into the fields and packing sheds. New challenges and opportunities will almost certainly arise in statistical analysis and reporting progress about progress in the vaccination campaign.

As the United States and the world moves onward into the phase of fighting the COVID-19 pandemic with vaccination campaigns and improved treatment options, there is the promise that improved approaches to collecting, analyzing, tabulating, and disseminating the statistical data can have a tangible positive impact by more effectively engaging the public in public health systems operational decision-making at the local level as well as at the state and national level.

\section{Acknowledgments}

I am grateful to Dr. Richard Mines for sharing tabulations of data on farmworker housing conditions in the Salinas Valley that provided a basis for a detailed analysis of the relationship between crowded housing and COVID-19 prevalence. Dr. Mines also very kindly shared insights from his analysis of the distribution of indigenous farmworker households in California.

I am also very grateful to Dr. Jo Ann Intili, my wife and co-trustee of the Werner-Kohnstamm Family Giving Fund, for her tireless partnership in our collaborative efforts since the pandemic began to advocate for enhanced strategies and effective interventions to combat COVID-19 in communities of farmworkers and immigrants.

Ongoing dialogue with fellow researchers and community activists working on behalf of farmworkers' and immigrants' well-being in the midst of the pandemic has been tremendously valuable in keeping me up to date on constant developments. Here in California I am particularly grateful to Noe Paramo of California Rural Legal Assistance Foundation, Oralia Maceda of the Centro Binacional Para el Desarollo Indigena Oaxaqueño, Jorge San Juan, Cindy Quezada at the Sierra Health Foundation, Naindeep Singh of The Jakara Movement, and Dr. Sergio Aguilar-Gaxiola at the Center for Reducing Health Disparities, University of California, Davis, as well as our longtime colleagues, Greg Asbed, Marley Moynahan, Gerardo Reyes, Laura Germino, and Lucas Benitez of the Coalition of Immokalee Workers in Florida, for sharing their insights and expertise about farmworkers and COVID19.

\section{References}

[1] U.S. Dept. of Labor. Accessing the Public Use Data Files; California National Agricultural Worker Survey Public Use Data 2014-2016 (weighted). 2020 (Sept 21). Available from: https://www.dol.gov/agencies/eta/national-agriculturalworkers-survey/data/accessing-data-files.

[2] Diamond D. Trump officials interfered with CDC reports on COVID-19. Politico. 2020 (Sept 11). Available from: https:// www.politico.com/news/2020/09/11/exclusive-trumpofficials-interfered-with-cdc-reports-on-covid-19-412809.

[3] Owermohle S. E-mails show HHS official trying to muzzle Fauci. Politico. 2020 (Sept 9). Available from: https://www. politico.com/news/2020/09/09/emails-show-hhs-muzzlefauci-410861

[4] Mandavilli A. After Criticism, CDC Reverses COVID-19 Guidelines, on Testing People who were Exposed, New York Times 2020 [updated 2020 Oct 2; cited 2020 Sept 18]. Available from: https//www.nytimes.com/2020/09/18/world/ 
covid-19-coronavirus.html?campaign_id=60\&emc=edit_na_ 20200918\&instance_id=0\&nl=breaking-news\&ref=cta\&regi _id $=55065485 \&$ segment_id=38479\&user_id=ce4adac3e6266 d74347fa786b2dc753f\#link-7adf3bad.

[5] Ballhaus R, Armour S, McKay B. A Demoralized CDC Grapples with White House Meddling and Its Own Mistakes. Wall Street Journal 2020 [cited 2020 Oct 15 11:42 EST]. Available from https//www.wsj.com/articles/ademoralized-cdc- grapples-with-white-house-meddling-andits-own-mistakes- 11602776561.

[6] Tobias M. Coronavirus outbreak at Fresno-area company has critics calling for more transparency. Fresno Bee. 2020 (July 10). Available from: https//www.fresnobee.com/news/coron avirus/article243972602.html.

[7] European Centre for Disease Prevention and Control. Event Background COVID-19. [updated 2020; Sept 24; cited 2020 Sept 9]. Available from: https//www.ecdc.europa.eu/en/novelcoronavirus/event-background-2019.

[8] Cheng A. Chinese Authorities Admit Improper Response to Coronavirus Whistleblower. National Public Radio 2020 Mar 19. Available from: https//www.npr.org/sections/coronaviruslive-updates/2020/03/19/818295972/chinese-authoritiesadmit-improper-response-to-coronavirus-whistleblower.

[9] Lacina L. Should you wear a face mask? WHO officials weigh in at today's COVID-19 briefing. World Economic Forum. 2020 Mar 30. Available from: https//www.weforum.org/ agenda/2020/03/who-should-wear-a-face-mask-30-marchwho-briefing/.

[10] Goodnough A, Sheikh K. CDC Weighs Advising Everyone To Wear A Mask. NYTimes 2020 [updated 2020 May 7; published 2020 Mar 31; cited 2020 Sept 9]. Available from: https//www.nytimes.com/2020/03/31/health/cdc-maskscoronavirus.html.

[11] He J, Guo Y, Mao R, Zhang J. Proportion of asymptomatic coronavirus disease 2019: A systematic review and metaanalysis. J Med Virol. 2020 Jul 21: 1-11. Available from: 10.1002/jmv.26326.

[12] Centers for Disease Control and Prevention. COVID-19 Pandemic Planning Scenarios. CDC 2020 [updated July 10, 2020]. Available from: https//www.cdc.gov/coronavirus/2019ncov/hcp/planning-scenarios.html.

[13] Barry R, Eastwood J, Overburg P. Coronavirus Hit the US. Long Before We Knew. Wall Street Journal. 2020 (Oct 9). Available from: https//www.wsj.com/articles/coronavirus-wasspreading-in-u-s-months-before-travel-bans-and-lockdowns11602277918.

[14] Moore JT, Ricaldi JN, Rose CE, et al. Disparities in Incidence of COVID-19 Among Underrepresented Racial/Ethnic Groups in Counties Identified as Hotspots During June 5-18, 2020-22 States, February - June 2020. MMWR Morb Mortal Wkly Rep 2020; 69: 1122-1126. doi: 10.15585/mmwr.mm6933e1.

[15] Artiga S, Corallo, B, Pham O. Racial Disparities in COVID-19: Key Findings from Available Data and Analysis, Kaiser Family Foundation, August 17, 2020 https://wwwkff.org/reportsection/racial-disparities-in-covid-19-key-findings-fromavailable-data-and-analysis-issue-brief/.

[16] Centers for Disease Control and Prevention. COVID-19 Hospitalization and Death by Race/Ethnicity. CDC; Coronovirus Disease 2019 (COVID-19); Cases Data \& Surveillance. 2020 [updated 2020 Aug 18]. Available from: https//www.cdc.gov/ coronavirus/2019-ncov/covid-data/investigations-discovery/ hospitalization-death-by-race-ethnicity.html

[17] U.S. Department of Labor. National Agricultural Worker Survey. Data Table 13 (California) - Hired Crop Worker De- mographics, California estimates 6 time periods. Available from: https//www.dol.gov/agencies/eta/national-agriculturalworkers-survey/research/data-tables.

[18] Rodriguez-Diaz CE, Guilamo-Ramos V, Mena L, Hall E, Honermann B, Crowley JS et al. Risk for COVID-19 infection and death among Latinos in the United States: examining heterogeneity in transmission dynamics. Annals of epidemiology. 2020; 10.1016/j.annepidem. 2020.07.007 Available from: https//jhu.pure.elsevier.com/en/publications/risk-for-covid19-infection-and-death-among-latinos-in-the-united.

[19] Jordan M, Oppel RA Jr., For Latinos and Covid-19, Doctors Are Seeing an 'Alarming' Disparity. New York Times; 2020 (May 8).

[20] Webb HM, Nápoles AM, Pérez-Stable EJ. COVID-19 and Racial/Ethnic Disparities. JAMA. 2020; 323(24): 2466-2467. doi: 10.1001/jama.2020.8598.

[21] Moore JT, Ricaldi JN, Rose CE, et al. Disparities in Incidence of COVID-19 Among Underrepresented Racial/Ethnic Groups in Counties Identified as Hotspots During June 5-18, 2020 - 22 States, February-June 2020. MMWR Morb Moral Wkly Rep 2020; 69: 1122-1126. doi: 10.15585/mmwr.mm69 33e1external.icon.

[22] U.S. Department of Labor. National Agricultural Worker Survey (NAWS). Employment and Training Administration. Available from: https://www.dol.gov/agencies/eta/nationalagricultural-workers-survey/research/data-tables.

[23] Cook L, Gray A. Official statistics in the search for solutions for living with COVID-19 and its consequences. Statistical Journal of the IAOS. 2020; 36(2); 253-278. doi: 10.3233/SJI200671.

[24] Kissam E. Keeping Farmworkers Safe At Work and At Home In The COVID-19 Pandemic. WKF Fund Working Paper. 2020 (March 28). Available from: http//www.wkfamilyfund. org/docs/.

[25] Delamater PL, Street EJ, Leslie TF, Yang Y, Jacobsen KH. Complexity of the Basic Reproduction Number $\left(R_{0}\right)$. Emerging Infectious Diseases. 2019; 25(1): 1-4. 10.3201/eid2501.171901. Available from: https//www.wkfam ilyfund.xgov/eid/article/25/1/17-1901.

[26] County of Los Angeles Public Health. LA County COVID19 Surveillance Dashboard. Available from: http//dashboard. publichealth.lacounty.gov/covid19_surveillance_dashboard/.

[27] Centers for Disease Control and Prevention (CDC). Worker Safety \& Support; Community, Work \& Schools: Workers and Employers: Agricultural Workers and Employers; Interim Guidance from CDC and the US. Department of Labor. 2020 (updated 2020 Jun 11). Available from: https//www.cdc.gov/ coronavirus/2019-ncov/community/guidance-agriculturalworkers.html.

[28] Sowder A. Dozens of Tennessee strawberry pickers test positive for COVID-19. The Packer. 2020 (June 30). Available from: https//www.thepacker.com/article/dozens-tennessee-str awberry-farm-workers-test-positive-covid-19.

[29] Bailey B. Dramatic increase in COVID-19 cases at Norfolk farm. Newburgh Gazette. 2020 (June 2).

[30] Wozniacka G. Farmworkers Are in the Coronavirus Crosshairs. Civil Eats. 2020 (Mar 25). Available from: https//civileats.com/ 2020/03/25/farmworkers-are-in-the-coronavirus-crosshairs/.

[31] Reyes J. Workers at SunDate packing facility test positive for coronavirus. News Channel 3; KESQ News. 2020 (April 2, published 4:56 pm). Available from: https//kesq.com/news/ 2020/04/02/workers-at-sundate-packaging-facility-testpositive-for-coronavirus/.

[32] Martin M. With tight living spaces and work that's not 
conducive to social distancing, $\mathrm{H}-2 \mathrm{~A}$ farmworkers are at risk. Santa Maria Sun. 2020 (Apr 1); 21, 5. Available from: http// www.santamariasun.com/cover/19537/with-tight-livingspaces-and-work-thats-not-conducive-to-social-distancingh2a-farmworkers-are-at-risk/.

[33] Botts J, Cimini K. "Investigation: COVID rips through motel rooms of guest workers who pick nation's produce", Cal Matters, September 4, 2020 https//calmatters.org/californiadivide/2020/08/guest-worker-covid-outbreak-california/.

[34] Garcia J. California Divide: Financial help for California's undocumented immigrants starts Monday. Cal Matters. 2020; [printed May 14, updated 2020 Sept 16]. Available from: https// calmatters.org/california-divide/2020/05/financial-helpavailable-californias-undocumented-immigrants-monday/.

[35] Hayes J, Hill L. Undocumented Immigrants in California. Public Policy Institute of California; Just the Facts. 2017 (March). Available from: https//www.ppic.org/publication/undocumen ted-immigrants-in-california/.

[36] Gabbard S, Fung W, Carroll D. Recent Changes in US. Agriculture and Crop Worker Characteristics. Presentation to 2020 Western Forum for Migrant and Community Health. 2020 (Feb 20).

[37] Kissam E. Why Special Help to Farmworker Families in Crowded Housing is So Important as Part of Overall Strategy to Suppress COVID-19. 2020 (April 7). Available from: http//www.wkfamilyfund.org/docs/.

[38] Mejia MC, Cha P. Overcrowded Housing and COVID-19 Risk among Essential Workers. Public Policy Institute of California. 2020 (March).

[39] Chamie G, Marquez C, Crawford E, et al. SARS-CoV-2 Community Transmission During Shelter-in-Place in San Francisco. (PrePrint). medRxiv, the Preprint server for Health Sciences. 2020 (June 17); doi: 10.1101/2020.06.15.20132233.

[40] Hernandez T, Gabbard S. Findings from the National Agricultural Workers Survey (NAWS) 2015-2016; A Demographic and Employment Profile of United States Farmworkers. U.S. Dept of Labor: Employment Training Administration. 2018 (June 28). pg. 18. Available from: https//www.doleta.gov/naws /research/docs/NAWS_Research_Report_13.pdf.

[41] Oatman M. Unsheltered in Place. Mother Jones. 2020 (Oct 2). Available from: https//www.motherjones.com/environment/ 2020/10/salinas-housing-coronavirus-farmworkers-wildfireslettuce-salad-crops/.

[42] Kissam E, Mines R, Quezada C, et. al. San Joaquin Valley Latino Immigrants: Implications of Survey Findings for Census 2020. The Center at Sierra Health Foundation (CA.): San Joaquin Valley Health Fund, San Joaquin Valley Census Research Project; 2019 (January). Available from: https//www. shfcenter.org/assets/SJVHF/SJVCRP_Survey_Findings_ Report_011819_Web.pdf.

[43] California Institute of Rural Studies. Preliminary Data Brief: Historic Pandemic Worsens Vulnerability of Essential Workers Who Feed Us All. COVID-19 Farmworker Study (COFS). 2020 (Jul 27). Available from: http//covid19 farmworkerstudy.org/preliminary-data/.

[44] U.S. Census Bureau. American Community Survey Narrative Profiles; 2014-2018 ACS 5yr Narrative Profile, California. Available from: https//www.census.gov/acs/www/data/datatables-and-tools/narrative-profiles/2018/report.php?geotype= state $\&$ state $=06$

[45] Aguirre International Division, JBS International. Identifying High Concentrations of Migrant and Seasonal Farmworkers. Final Report to the Population Division, U.S. Census Bureau, 2007.
[46] Mines R. Salinas Pajaro Valley Farmworker Housing Survey. In: Wadsworth G, VIllarejo D, et al. Farmworker Housing Study and Action Plan for Salinas Valley and Pajaro Valley. CA: California Institute of Rural Studies. 2018 (June). pp. 141-203. Available from: https//donvillarejo.github.io/ Fulltext/Farmworker-Housing-Study-and-Action-Plan-forSalinas-Valley-and-Pajaro-Valley_2018-Jume.pdf.

[47] California Department of Public Health. COVID-19: Blueprint for a Safer Economy. 2020 (Sept 23). Available from: https// www.cdph.ca.gov/Programs/CID/DCDC/Pages/COVID19/COVID19CountyMonitoringOverview.aspx.

[48] Gardner L, Dong E, Hongru E. An interactive web-based dashboard to track COVID-19 in real time. Lancet Infect Dis. 2020 May; 20(5): 533-534. doi: 10.1016/S1473-3099(20)30120-1. Epub 2020 Feb 19. Available from: https//pubmed.ncbi.nlm. nih.gov/32087114/.

[49] Gottlieb S, McClellan M, Silvis L, et al. National Coronavirus Response: A Road Map To Reopening. American Enterprise Institute. 2020 (Mar 9). Available from: https//www.aei.org/ research-products/report/national-coronavirus-response-aroad-map-to-reopening/.

[50] Resolve To Save Lives. Tracking COVID-19 in the United States: From Catastrophe to Empowered Communities. 2020 (Jul 21). Available from: https//preventepidemics.org/wpcontent/uploads/2020/07/RTSL_Tracking-COVID-19-in-theUnited-States_-7-23-2020.pdf.

[51] Fresno County Administrative Office. CARES Act Funding and the Coronovirus Relief Fund. Available from: https://www. co.fresno.ca.us/departments/county-administrative-office/ cares-act-funding.

[52] Center of Disease Control (CDC). Managing Investigations During an Outbreak. CDC; Coronovirus Disease 2019 (COVID-19); Health Departments. 2020 [Updated 2020 July 31]. Available from: https//www.cdc.gov/coronavirus/2019ncov/php/contact-tracing/contact-tracing-plan/outbreaks. html.

[53] Tufekci Z. The Overlooked Variable Driving the Pandemic. The Atlantic. 2020 (Sept 30). Available from: https//www. theatlantic.com/health/archive/2020/09/k-overlookedvariable-driving-pandemic/616548/.

[54] Merced County Dept of Public Health. Statement Regarding COVID-19 Outbreak at Foster Farms Facility in Livingston. 2020 (Aug 27). Available from: https//www.co.merced.ca.us/ DocumentCenter/View/25497/MCDPH-Foster-Farms-State ment-82720?bidId $=$.

[55] Local News. Update of statement regarding COVID-19 outbreak at Foster Farms Facility in Livingston. Merced County Times. 2020 (Aug 27). Available from: https//mercedcounty times.com/state-county-health-officials-call-for-closure-offoster-farms-poultry-processing-plant-in-livingston/.

[56] Luiz J. UFW files charges against Primex Farms for allegedly firing employees who said company wasn't protecting them from COVID-19. KGET (KGET.COM) 2020 [updated 2020 July 28,7:50pm PDT). Available from: https//www.kget.com/ health/coronavirus/ufw-files-charges-against-primex-farmsfor-allegedly-firing-employees-who-said-company-wasntprotecting-them-from-covid-19/.

[57] Splitter J. 'Everybody's Infected': 76 Farmworkers Test Positive In New Coronavirus Outbreak. Forbes. 2020 (Jul 2). Available from: https//www.forbes.com/sites/jennysplitter/ 2020/07/02/primex-farms-coronavirus-outbreak/\#443655 $\mathrm{d} 15 \mathrm{e} 01$.

[58] De Rosa T. Primex deals with Outbreak. Wasco Tribune. 2020 
(July 9). Available from: https//www.wascotrib.com/story/ 2020/07/09/news/primex-deals-with-outbreak/1537.html.

[59] Rode E. Following Santa Barbara, Ventura County Enacts New Protections for Certain Farmworkers. VC Star. News. 2020 (Sept 18, 10:15a.m. Pacific Time). Available from: https//www.vcstar.com/story/news/2020/09/18/santabarbara-county-ventura-county-increase-h-2-a-worker-prote ctions/3482985001/https://www.nytimes.com/2020/03/31/ health/cdc-masks-coronavirus.html.

[60] California Department of Public Health. COVID-19: Blueprint for a Safer Economy: Health Equity Focus. 2020 (Sept 30) Available from: https//www.cdph.ca.gov/Programs/CID/ DCDC/Pages/COVID-19/CaliforniaHealthEquityMetric.aspx.

[61] The Rockefeller Foundation. National COVID-19 Testing Plan. 2020 (July). Available from: https//www.rockefellerfoundati on.org/national-covid-19-testing-action-plan/.

[62] Mina MJ, Parker R, Larremore DB. Rethinking Covid-19 Test Sensitivity - A Strategy for Containment. New England Journal of Medicine; Perspective. 2020 (Sept 30) doi: 10.1056/NEJMp2025631 Available from: https//www.nejm.org/doi/full/10. 1056/: NEJMp2025631.

[63] Center for Disease Control and Prevention (CDC). COVID_19 Pandemic Planning Scenarios. CDC; Coronovirus Disease 2019 (COVID-19); Healthcare Workers. 2020 [Updated 2020 Sept 10]. Available from: https//www.cdc.gov/coronovirus/ 2019-ncov/hcp/planning-scenarios.html.

[64] Paltiel D, Walensky R. Screening To Prevent SARS-CoV-2 Outbreaks: Saliva-Based Antigen Testing Is Better Than The
PCR Swab. Health Affairs. 2020 (Sept 11). Available from: https//www.healthaffairs.org/do/10.1377/hblog20200909.430 047/full/.

[65] Daley J. Millions of Rapid Antigen Tests May Help Fill the Testing Gap. Scientific American, 2020 (May 7) Available from: https//www.scientificamerican.com/article/millions-ofrapid-covid-19-antigen-tests-may-help-fill-the-testing-gap/.

[66] Ahmed A. Hidden Toll: Mexico Ignores Wave of Coronavirus Deaths in Capital. New York Times. 2020 (May 8). Available from: https//www.mcall.com/coronavirus/sns-nytgovernment-ignores-virus-deaths-mexico-city-20200508aymbz2srkjgqhhjal2sionbwuu-story.html.

[67] Lopez G. Trump asked for fewer COVID-19 tests. Now The CDC is Recommending Less Testing. Vox. 2020 (Aug 27). Available from: https//www.vox.com/2020/8/26/21403000/ trump-covid-coronavirus-testing-cdc-hhs.

[68] Higgins-Dunn N. Trump Says US. Would Have Half the Number of Coronavirus Cases If It Did Half The Testing. CNBC. 2020 [Jul 14; updated 2020 Jul 15 6:30pm EDT] Available from: https//www.cnbc.com/2020/07/14/trumpsays-us-would-have-half-the-number-of-coronavirus-casesif-it-did-half-the-testing.html.

[69] Hansen S. Fauci Says It Will Be Well Into 2021 Before US. Returns to Normal From Coronavirus. Forbes. 2020 (Sept 11). Available from: https//www.forbes.com/sites/sarahh ansen/2020/09/11/fauci-says-it-will-be-well-into-2021before-us-returns-to-normal-from-coronavirus/\#4a571bef2 $\mathrm{f} 7 \mathrm{c}$ 